\title{
Metal Organic Frameworks as Biosensing Materials for COVID-19
}

\author{
Godwin A. Udourioh, ${ }^{1}$ Moses M. Solomon (i), ${ }^{2}$ and Emmanuel I. Epelle ${ }^{3}$ \\ ${ }^{1}$ Analytical/Material Chemistry Laboratory, Department of Pure and Applied Chemistry, Faculty of Natural and Applied \\ Sciences, Veritas University, Abuja, P.O.Box 6523, Garki, Abuja, Nigeria; ${ }^{2}$ Department of Chemistry, College of Science and \\ Technology, Covenant University, Canaanland, Km10, Idiroko Road, Ota, Ogun State, Nigeria; and ${ }^{3}$ Institute for Materials and \\ Processes (IMP), School of Engineering, University of Edinburgh, The King's Buildings, Edinburgh EH9 3FB, UK
}

(Received 5 April 2021; accepted 21 June 2021; published online 6 July 2021)

Associate Editor Michael R. King oversaw the review of this article.

\begin{abstract}
The novel coronavirus disease (COVID-19) pandemic outbreak is the most startling public health crises with attendant global socio-economic burden ever experienced in the twenty-first century. The level of devastation by this outbreak is such that highly impacted countries will take years to recover. Studies have shown that timely detection based on accelerated sample testing and accurate diagnosis are crucial steps to reducing or preventing the spread of any pandemic outbreak. In this opinionated review, the impacts of metal organic frameworks (MOFs) as a biosensor in a pandemic outbreak is investigated with reference to COVID19. Biosensing technologies have been proven to be very effective in clinical analyses, especially in assessment of severe infectious diseases. Polymerase chain reactions (PCR, RTPCR, CRISPR) - based test methods predominantly used for SARS-COV-2 diagnoses have serious limitations and the health scientists and researchers are urged to come up with a more robust and versatile system for solving diagnostic problem associated with the current and future pandemic outbreaks. MOFs, an emerging crystalline material with unique characteristics will serve as promising biosensing materials in a pandemic outbreak such as the one we are in. We hereby highlight the characteristics of MOFs and their sensing applications, potentials as biosensors in a pandemic outbreak and draw the attention of researchers to a new vista of research that needs immediate action.
\end{abstract}

Keywords-Covid-19, Biosensors, Metal organic frameworks, Infectious diseases testing and detection, Pandemic outbreak.

Address correspondence to Moses M. Solomon, Department of Chemistry, College of Science and Technology, Covenant University, Canaanland, Km10, Idiroko Road, Ota, Ogun State, Nigeria. Electronic mail: moses.solomon@covenantuniversity.edu.ng

\section{INTRODUCTION}

As at $6.03 \mathrm{pm}$ CEST, 10 March, 2021, there have been 118,684,343 COVID-19 cases, including 2,633,281 deaths confirmed globally by WHO, ECDC, NCDC and John Hopkins University. ${ }^{120}$ Since the first case of COVID-19 was detected in China's Hubei province in late 2019, stringent measures such as lockdowns, travel bans, border closure etc. have been imposed in order to control or stop the spread of the outbreak, yet the global spread of the virus has continued to record significant increase with attendant global socio-economic burden. ${ }^{31,88}$ In fact, reports from WHO and John Hopkins University reveals that the second wave of the outbreak is more devastating thus has left people in great fear. ${ }^{93}$

Sample testing is an essential first step to responding to any pandemic outbreak. ${ }^{31,45}$ Diagnosis plays a decisive role in making prompt decisions on detection, contact tracing, isolation, management and treatment of infected persons. ${ }^{45}$ However, in the ongoing COVID-19 outbreak, most countries are unable to meet up with the massive diagnostic testing order given by WHO. ${ }^{79,83,86}$ This has resulted in a continuous spread due to community transmission. ${ }^{79,86}$

As suggested by WHO, the general benchmark for adequate testing for a positive rate is around $3-12 \%$ per 1000 persons. ${ }^{23}$ South Korea, Uruguay, Germany and Australia recorded a positive rate of $1 \%$ hence being considered as countries with lowest COVID-19 related deaths in the world. ${ }^{24,37}$ South Korea was able to achieve the feat through their intensive testing programs occasioned by "drive-through" and "phone booths" tests. ${ }^{81}$ On the other hand, countries like Mexico and Nigeria have positive rates of $20-50 \%$ (a case is found for every few tests conducted), indicating the unlikelihood of testing widely enough to find all 
cases. ${ }^{37}$ No wonder the number of new confirmed cases keep increasing daily. ${ }^{120}$

Apart from the disparity in country's political and policy frameworks which may hinder the control of the continuous spread of the pandemic, the biosensing technologies (technologies behind testing and diagnosis) are important factors to consider. A biosensor is a device used for the detection of biological and biochemical agents; employing a biologically derived or a biomimetic recognition element while either undergoing a biochemical reaction (for example, enzyme-based biosensors) or binding the target molecule in a highly specific way. Studies have shown that biosensing devices, materials or technologies for testing infectious diseases or at time of pandemic outbreak must rigorously satisfy requirements of accessibility and affordability, rapidity, high sensitivity and selectivity, robustness, flexibility and simplicity in usage, ability to be mass produced etc. ${ }^{15,81}$

The present trend in the daily reports on the confirmed cases of the COVID-19 globally may be a pointer to the fact that the biosensing technologies currently in used for SARS-COV-2 testing are not satisfactory. It is pertinent to review the type of assays, strength and limitations of the commonly used biosensing methods since the pandemic outbreak and explore the potentials of other versatile biosensing materials and technologies such as metal organic frameworks (MOFs) for possibility of development and utilization in solving diagnostic problem associated with the current and future pandemic outbreaks.

\section{METAL ORGANIC FRAMEWORKS (MOFS) AND THEIR CHARACTERISTICS}

Metal Organic Frameworks (MOFs) are advanced structures that are highly ordered, porous and customizable. They grow in a crystal form and are extremely flexible, especially when combined with nanoparticles for additional functionality or attributes. $^{70,137}$ MOFs are made of metal clusters coordinated with organic linkers to generate a large Langmuir surface area and small-to-medium-sized pores. ${ }^{54}$ MOFs are defined as porous structures constructed from the coordinative bonding between metal ions and organic ligands or bridging ligands. ${ }^{138}$ The linkers or bridging ligands consist of carboxylates, or anions, such as phosphonate, sulfonate, and heterocyclic compounds while the inorganic units are the metal ions or clusters called secondary building units (SBUs). ${ }^{138}$ The coordination number, geometry of the metal ions and the nature of the functional groups determine the geometry of MOFs. Based on this we have octahedron with six points of extension, trigonal prism with five points, square paddle-wheel (four points), and triangle with three points. Some commonly used metals for synthesis of MOFs include La, $\mathrm{Zn}, \mathrm{Cr}, \mathrm{Cu}$, In $\mathrm{Co}, \mathrm{Fe}$ and $\mathrm{Ag}$ while some common organic linkers or ligands include 1,4-benzenedicarboxylate or terephthalate moiety $\left(\mathrm{H}_{2} \mathrm{bdc}\right)$, Benzene1,3,5-tricarboxylate moiety $\left(\mathrm{H}_{3} \mathrm{btc}\right), \quad 4,4^{\prime}$ biphenyldicarboxylate $\left(\mathrm{H}_{2} \mathrm{bpdc}\right)$, 1,4-bis(imidazol-1ylmethyl)benzene (Bix), 1,3,5-benzenetriphosphoric acid, 1,5-naphthalenedisulfonic acid, 4,4-bipyridine, 2,5-dihydroxybenzene-1,4-dicarboxylic acid ( $\left.\mathrm{H}_{4} \mathrm{dhbdc}\right)$, 2,6-naphthalenedicarboxylic acid $\left(\mathrm{H}_{2} \mathrm{ndc}\right)$, adamantane tetracarboxylic acid $\left(\mathrm{H}_{4}\right.$ atc $), 4,4^{\prime}, 4^{\prime \prime}$-benzene-1,3,5-tryyl-benzoic acid $\left(\mathrm{H}_{3} \mathrm{btb}\right){ }^{138}$ Figure 1 shows the typical skeletal structure of MOF and some examples of ligand structures.

MOFs are often synthesized using solvothermal, ionothermal, diffusion, microwave, ultrasound-assisted and template-directed syntheses methods. ${ }^{33,65,128,143}$ Figure 2 shows the different synthesis methods for MOFs. MOFs may be classified based on the type of metals and guest species into five categories, viz. transition metal MOFs, rare earth metal (REM) MOFs, composite structure MOFs, heterometallic MOFs, and S-block metal MOFs. ${ }^{103}$ Most MOFs are simply named after the institutions from where they were produced. Examples include MIL-101 $\left[\mathrm{Cr}_{3} \mathrm{O}(\mathrm{OH}\right.$, $\left.\mathrm{F}, \mathrm{H}_{2} \mathrm{O}\right)_{3}(1,4-\mathrm{bdc})_{3}$ ] and other MIL-series named after Materials Institute Lavoisier and commonly used for drug delivery, ${ }^{48}$ HKUST-1 $\left[\mathrm{Cu}_{2}\left(\mathrm{H}_{2} \mathrm{O}\right)_{2}\left(\mathrm{CO}_{2}\right)_{4}\right]$ named after Hong Kong University of Science and used for adsorption and storage, ${ }^{67} \mathrm{UiO}-66-\mathrm{NH}_{2}$ named after University of Oslo and used for biosensing ${ }^{121}$ and an isoreticular MOF IRMOF-9 [ $\left.\mathrm{Zn}_{4} \mathrm{O}(\mathrm{bpdc})_{3}\right]$ used for adsorption and storage. ${ }^{95}$ In comparison to other highclass materials such as graphenes, carbon nonatubes, gold nonatunes etc., MOFS are emerging class of porous inorganic-organic high profile hybrid compounds which have attracted much attention in recent time due to its stunning properties and wider applications. ${ }^{75}$ Figure 3 shows comparison of MOFs with other materials in terms of properties.

\section{MOFS AS BIOSENSORS}

There are different sensing platforms, viz. luminescence, surface plasmon resonance, electrochemical, impedance, fluorescence imaging (magnetic resonance imaging MRI), interferometry and solvatochromism. ${ }^{18,49,69,97,98,142}$ Recently, MOFs have been explored as Biological and biochemical sensors. ${ }^{11,36}$ $\mathrm{Hao}$ and $\mathrm{Yan}^{36}$ developed a lanthanide-functionalized $\mathrm{MOF}$ as a fluorescent probe for hippuric acid in urine which was considered as the biological indicators of 


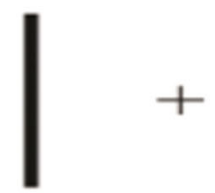

Organic Linker

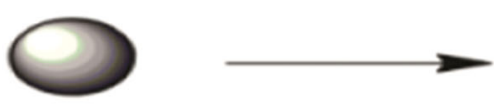

Metal ions or clusters

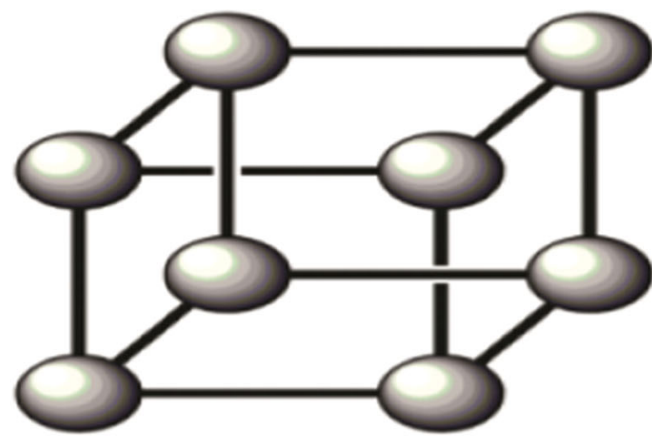

MOF

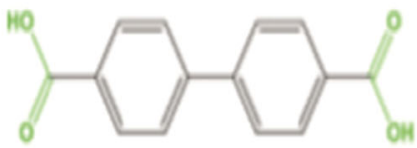

H, bpde: biphenyl4,4'dicarberylic add

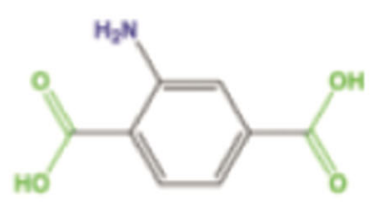

$\mathrm{H}_{2}$ Nbdc: 2 -aminoterephthalic acid

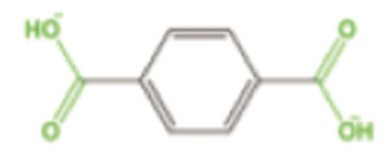

H,bde: Terephthaalie acid<smiles>c1cn(Cc2ccc(Cn3ccnc3)cc2)cn1</smiles>

1,4-bis(imidazol-1-ylmethyl)benzene (bix)

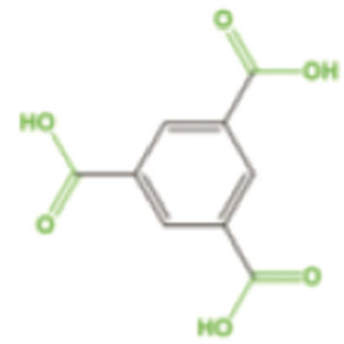

H,bte: 1,3,5-benuenetricarbexylic acid<smiles>O=P(O)(O)c1cc(P(=O)(O)O)cc(P(=O)(O)O)c1</smiles>

3,5-benzenetriphosphoric acid<smiles>O=S(=O)(O)c1cccc2c(S(=O)(=O)O)cccc12</smiles>

1,5-naphthalenedisulfonic

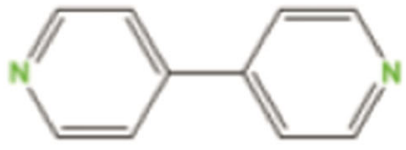

4,4'-bipyridine

FIGURE 1. Typical Structure of MOF and Some examples of organic linkers of ligands. Adapted from Sharmin and Zafar. ${ }^{137}$ (C) 2016 The Author(s).

toluene exposure. The fabricated sensor, according to the authors has several attractive features, including high sensitivity, excellent selectivity, fast response time $(\sim 1 \mathrm{~min})$, broad linear range $(0.05-8.0 \mathrm{mg} / \mathrm{mL})$, and good reversibility and regeneration. ${ }^{36}$ The sensor was successfully applied to determination of hippuric acid in human urines with recoveries in the range of 93.5$102.9 \%$. The high porosity, tuneable chemical composition, large surface area, high crystallinity, and potential for post synthetic modification for molecular recognition have made MOFs promising candidates for biosensing application. ${ }^{80}$ Besides, the inherent luminescence of many MOFs have made it useful in sensing platforms. ${ }^{97,98}$ Some MOFs and their biosensing applications are summarized in Table 1. 

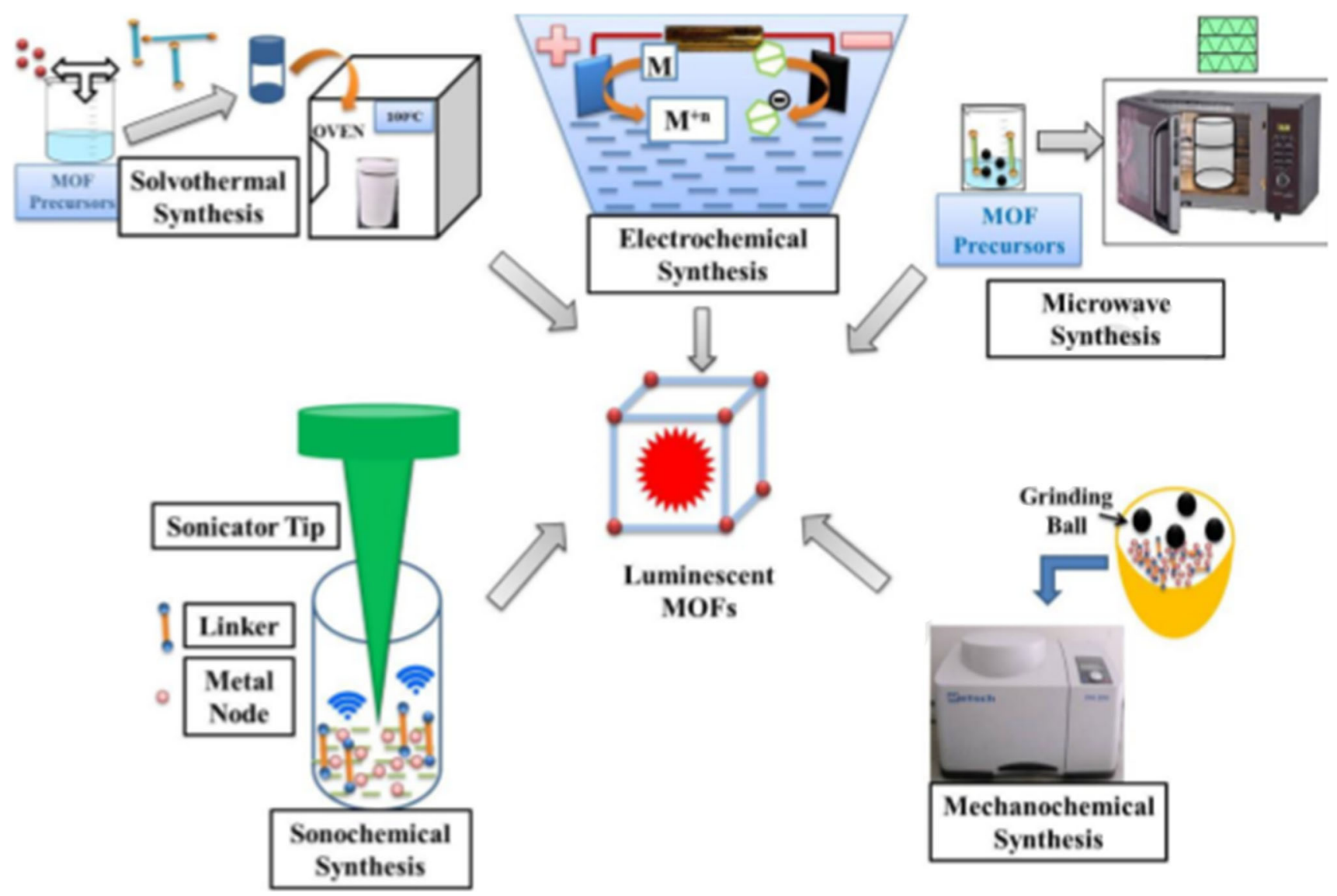

FIGURE 2. Schematic of commonly used approaches for high-throughput synthesis of MOFs. Reproduced with permission from Kukkar et al. ${ }^{50}$. (C) 2018 Elsevier B.V.

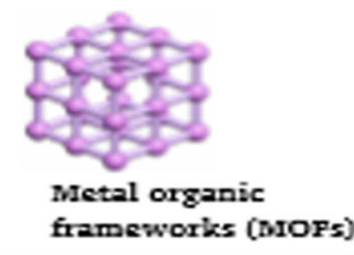

i. Large specific surface area $(10,400 \mathrm{~m} 2 / \mathrm{g})$

ii. High porosity $(90 \%)$;

iii. Thermally stable;

iv. Water stable;

v. Tunable pore sizes (from micropore to mesopore);

vi. Highly ordered

vii. High loading efficiency;

viii. Uniform structural Nano scale cavities

ix. Easy functionalization and postsynthetic modification;

x. Biocompatible and biodegradable.

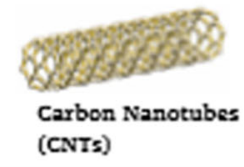

i. Electric conductive;

ii. High surface area;

iii. Rich in oxygen functional groups at the end and the side of the wall for ligand immobilizing;
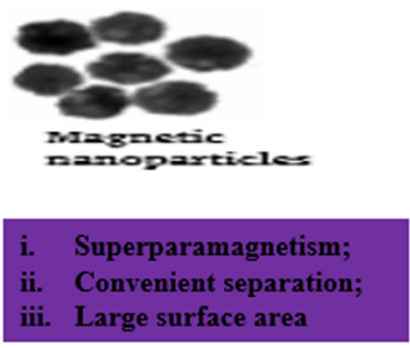

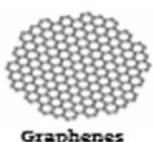

Graphenes

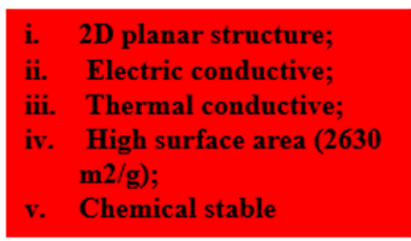
(AuNTs)
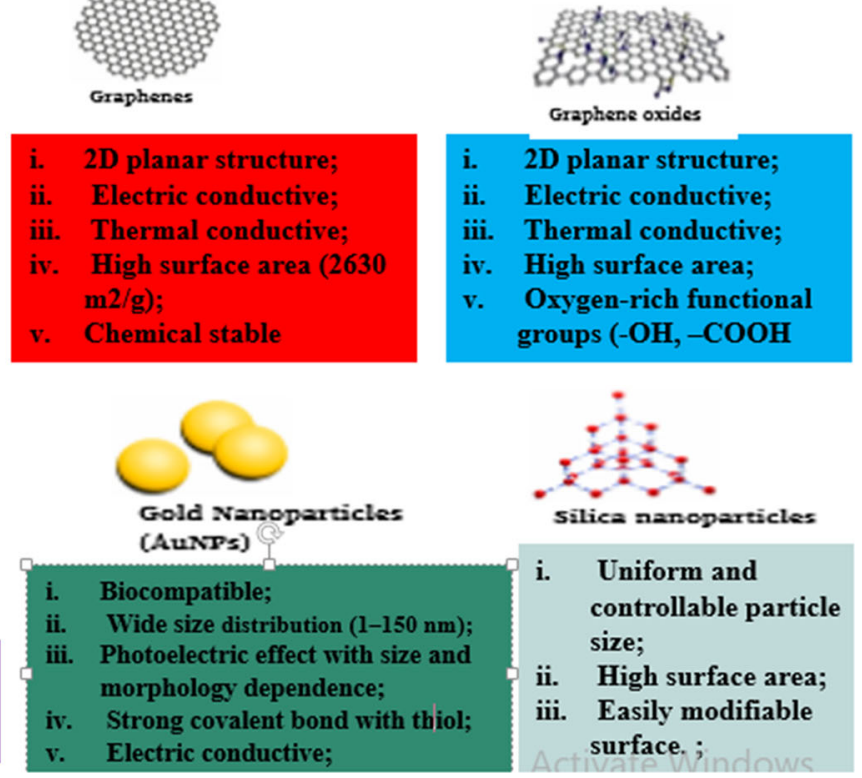

Graphene oxides

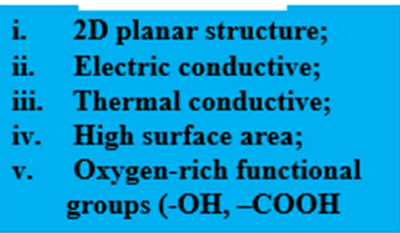

groups $(-\mathrm{OH},-\mathrm{COOH}$

FIGURE 3. Stunning Properties of MOF Compared to other high class materials. 


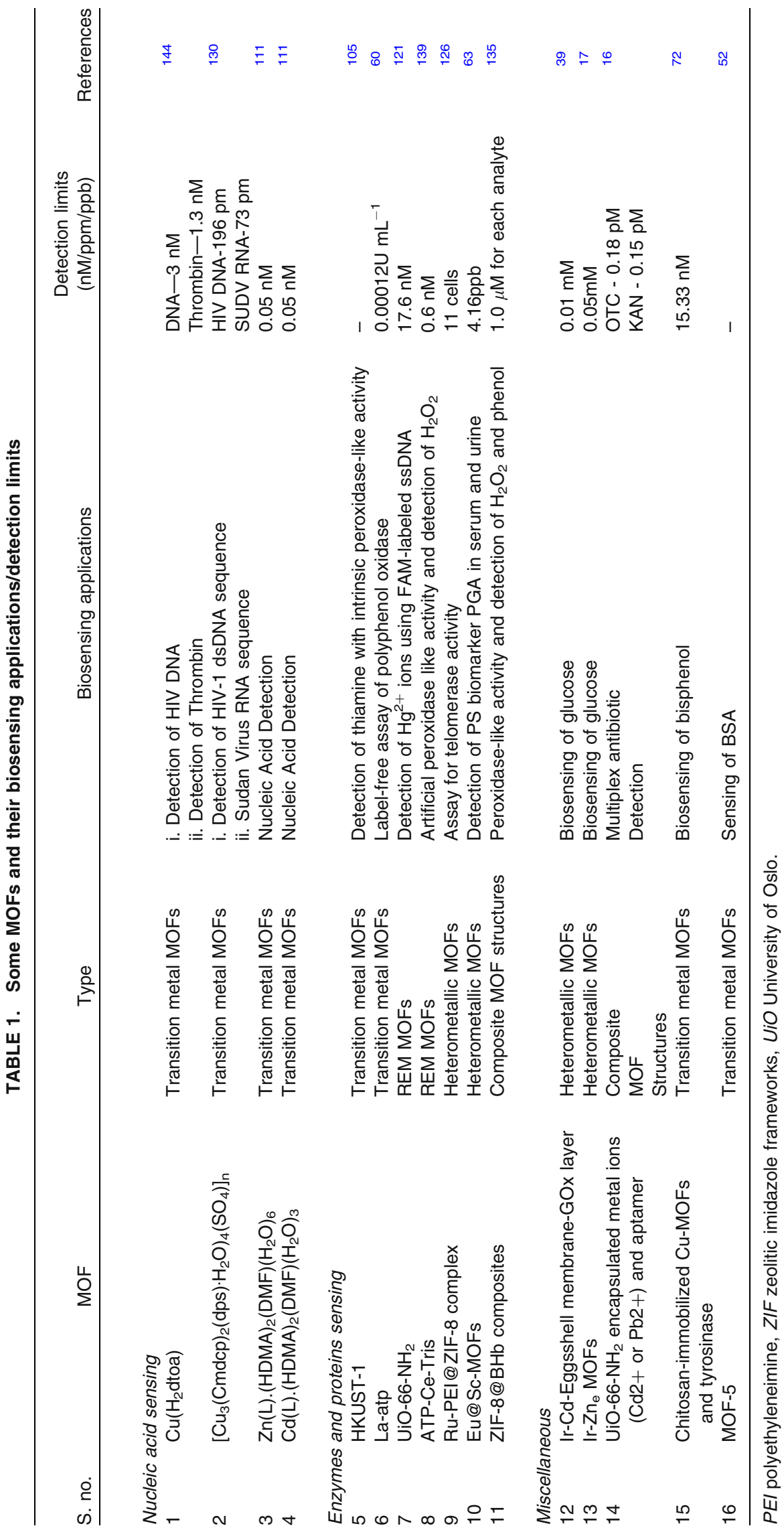



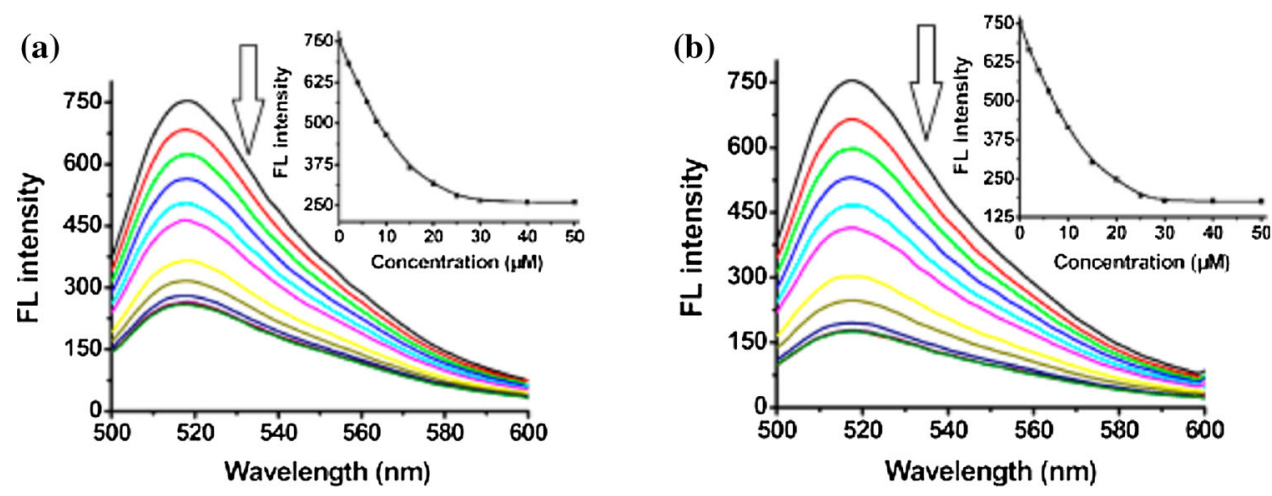

FIGURE 4. Fluorescence spectra of P-DNA-1 (a, $50 \quad \mathrm{nM})$ and P-DNA-2 (b, 50 nM) incubated with MOF $\left[\mathrm{Cu}_{3}(\mathrm{Cmdcp})_{2}(\mathrm{dps})_{4} \cdot\left(\mathrm{H}_{2} \mathrm{O}\right)_{4}\left(\mathrm{SO}_{4}\right)\right]$ n of varying concentrations at room temperature. Insets: plots of fluorescence intensity at 518 $\mathrm{nm}$ versus the concentrations of MOF $\left[\mathrm{Cu}_{3}(\mathrm{Cmdcp})_{2}(\mathrm{dps})_{4} \cdot\left(\mathrm{H}_{2} \mathrm{O}\right)_{4}\left(\mathrm{SO}_{4}\right)\right]$. Reproduced with permission from Yang et al. ${ }^{129}$. (C) 2015 American Chemical Society.

\section{MOFS AS BIOSENSING MATERIALS IN PANDEMIC OUTBREAKS}

Viruses are often the culprit in epidermic and pandemic outbreaks. They are infectious agents, mostly in nanoscale capable of causing various diseases. ${ }^{82}$ MOFs have been used as biosensors during epidermic and pandemic outbreaks.

\section{Sensing of Human Immunodeficiency Virus}

The retrovirus is a RNA virus whereby its DNA is integrated into its host chromosomal DNA. ${ }^{8,82}$ Detection at the early stage of infection may be difficult due to the rare proviral DNA expression in the infected host. ${ }^{99}$ The Human Immunodeficiency Virus (HIV), which belongs to the genus Lentivirus within the family of Retroviridae and subfamily Orthoretrovirinae $^{99}$ is a human retrovirus. Based on the genetic characteristics and differences in the viral antigens, there are two types of HIV: HIV-1 and HIV-2. ${ }^{99,100}$ The HIV-1 type is believed to have evolved from nonhuman primate immunodeficiency viruses from the Central African chimpanzees (SIVcpz) ${ }^{30,32}$ while the HIV-2 type is linked to the West African sooty mangabeys (SIVsm) as the origin. ${ }^{100}$ HIV infection results in acquired immunodeficiency syndrome (AIDS), a disease that is associated with the depletion of the $\mathrm{CD}_{4}{ }^{+} \mathrm{T}$ cell of the host. ${ }^{8}$ According to the WHO, at the end of 2019, an estimated 38.0 million people are living with HIV and about 33 million deaths have resulted from AIDS-related sicknesses. ${ }^{118}$ Because early diagnosis and treatment of HIV can improve survival and reduce morbidity, the Centers for Disease Control and Prevention have recommended routine testing. ${ }^{4}$ Examples of such routine test are the western blot and enzyme-linked immunosorbent assay (ELISA) assay. ${ }^{82}$ Nevertheless, because of reaction of samples with one or more of the antigens, these methods suffer from some false positive and negative outcomes. ${ }^{82}$ Researchers have taken advantage of large specific surface area, high porosity, fluorescence quenching, high loading efficiency, easy functionalization, and tunable pore properties of MOFs to deploy them in biosensing applications including the biosensing of HIV.

Yang et al. ${ }^{130}$ applied $\left[\mathrm{Cu}_{3}(\mathrm{Cmdcp})_{2}(\mathrm{dps})_{4} \cdot\left(\mathrm{H}_{2} \mathrm{O}\right)_{4}\left(\mathrm{SO}_{4}\right)\right] \mathrm{n}$ for the detection of human immunodeficiency virus-1 double-stranded DNA (HIV-1 ds-DNA). The 3-dimentional structure of the MOF enhanced the distinction between the dsDNA and ss-DNA molecules. The intrinsic quenching properties of the unsaturated $\mathrm{Cu}$ (II) metal ion coordination centre and the conjugated $\pi$-electron system of the aromatic groups on both linkers enabled electrostatic and hydrogen bonding via $\pi$-stacking interactions of the probe DNAs with the MOF, leading to photoinduced electron transfer (PET) fluorescence quenching. There was also a strong interaction between the probe DNA and the target DNA sequence. The non-target DNA sequences were between 50 and $86 \%$ less fluorescence than the target sequence in the dsDNA assay due to the diminished effect of its concentration. The probe recorded a high selectivity and $196 \mathrm{pM}$ detection limit for the viral dsDNA. ${ }^{130}$ Notably, the interaction of the MOF $\left[\mathrm{Cu}_{3}(\mathrm{Cmdcp})_{2}(\mathrm{dps})_{4} \cdot\left(\mathrm{H}_{2} \mathrm{O}\right)_{4}\left(\mathrm{SO}_{4}\right)\right] \mathrm{n}$ with the complimentary sequences of HIV ds-DNA: carboxyfluorescein FAM-labeled probe ss-DNA, 5'-FAMTTCTTCTTTTTTCT-3' (P-DNA-1) and SUDV RNA: 5-FAM-TTAAAAAGTTTGTCCTCATC-3 (PDNA-2) showed that the fluorescence intensity of the complimentary sequences of both HIV ds-DNA and SUDV RNA decreased upon the addition of the MOF. The quenching efficiency $\left(\mathrm{Q}_{\mathrm{E}} \%\right)$ of both HIV ds-DNA and SUDV RNA sequences were 65 and $76 \%$ respectively, indicating that the MOF efficiently quenched 

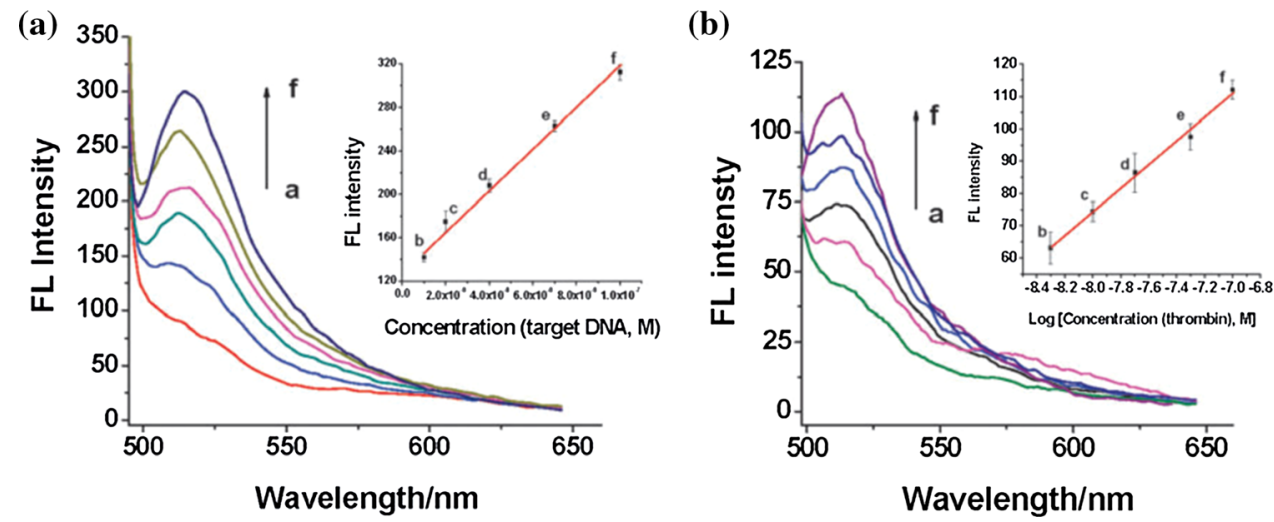

FIGURE 5. (a) Fluorescence spectra of the FAM-labeled DNA-Cu( $\left.\mathrm{H}_{2} \mathrm{dtoa}\right)$ in the presence of different concentrations of target DNA. Inset: plot of fluorescence intensity vs. concentrations of target DNA. (b) Fluorescence spectra of the FAM labeled probe DNA 2-Cu( $\mathrm{H}_{2}$ dtoa) in the presence of different concentrations of thrombin. Inset: plot of fluorescence intensity vs. logarithm of concentrations of thrombin. The concentration of dye-labeled probe DNA 1and DNA 2 is $50 \mathrm{nM}$. Reproduced with permission from Zhu et $a .^{143}$ (C) Royal Society of Chemistry 2013) and Miller et al..$^{80}$ (C) 2016 The Authors).

the fluorescence of both P-DNA-1 and P-DNR-2 sequences. The fluorescence spectra of both HIV-1 dsDNA and SUDV RNA complementary sequences are presented in Fig. 4.

Zhu et al. ${ }^{144}$ reported the successful application of a 2-D transition metal MOF $\mathrm{Cu}\left(\mathrm{H}_{2}\right.$ dtoa) [i.e. $\mathrm{N}, \mathrm{N}^{\prime}$ bis(2-hydroxyethyl)dithiooxamidatocopper(ii)] for detection of HIV-1 U5 long terminal repeat DNA sequence with detection limits of $3 \mathrm{nM}$, high sensitivity and selectivity. The mechanism of action was enhanced by the intrinsic quenching properties of the metal ion $\mathrm{Cu}^{2+}$, coordination centre and conjugated $\pi$-electron system of the dithiooxamide linkers. These properties led to the non-covalent binding of the 6-carboxyfluorescein or FAM single stranded DNA (ssDNA) probe via $\pi$-stacking interactions with the MOF, which quenched its fluorescence in a process called photo induced electron transfer (PET) ${ }^{80,144}$ There occurred a turn-on sensing of the viral gene when the target DNA was added due to the release of the probe from the MOF and the fluorescence restoration. ${ }^{80}$ The probeMOF exhibits a linear increase in the range of 10 $100 \mathrm{nM}$ and the sensor system was believed to be highly sensitive and selective. The Fluorescence spectra of the FAM-labeled DNA- $\mathrm{Cu}\left(\mathrm{H}_{2}\right.$ dtoa $)$ in the presence of different concentrations of target DNA is shown in Fig. 5a. Similarly, Fig. 5b depicts the fluorescence spectra of the FAM labeled probe DNA $2-\mathrm{Cu}\left(\mathrm{H}_{2}\right.$ dtoa $)$ in the presence of different concentrations of thrombin.

Zhao et $a l .{ }^{140}$ isolated six water-stable zinc(II) zwitterionic carboxylate compounds with 1D chain, 2D networks and 3D MOFs structures through the coordination reaction of $\left\{\mathrm{Na}_{3}\left[\mathrm{Na}_{9}\right.\right.$ (Cbdcp) $\left.\left.{ }_{6}\left(\mathrm{H}_{2} \mathrm{O}\right)_{18}\right]\right\}_{\mathrm{n}}$ with $\mathrm{Zn}\left(\mathrm{NO}_{3}\right)_{2} \cdot 6 \mathrm{H}_{2} \mathrm{O}$. Among the isolated compounds, the $2 \mathrm{D}$ sheet, $\left\{\left[\mathrm{Zn}(\mathrm{Cbdcp})(\mathrm{bpe})_{1 /}\right.\right.$ $\left.\left.{ }_{2}\right] \cdot 2 \mathrm{H}_{2} \mathrm{O}\right\} \mathrm{n}$ compound was found to efficiently quen- ched the fluorescence of P-DNA. The authors had selected a FAM-labeled P-DNA 50-FAMTTCTTCTTTTTTCT-30 as complementary sequences for HIV ds-DNA and noticed that the fluorescence intensity of P-DNA decreased upon the addition of $\left\{\left[\mathrm{Zn}(\mathrm{Cbdcp})(\mathrm{bpe})_{1 / 2}\right] \cdot 2 \mathrm{H}_{2} \mathrm{O}\right\} \mathrm{n} \quad$ compound. The quenching efficiency $(\mathrm{QE} \%)$ was $73 \%$ with the saturation concentration calculated as $10 \mathrm{mM}$. It was proposed that the compound formed a noncovalent complex P-DNA@2 system with its functional aromatic rings, the carboxylic acid groups, the positively charged pyridinium and $\mathrm{Zn}^{2+}$ cation centers and 2D plane structure (Fig. 6).

\section{Sensing of Ebola Virus (Sudan Virus) RNA Sequence}

Ebola virus disease (EVD), formerly known as Ebola haemorrhagic fever is a viral hemorrhagic fever of humans and other primates that first appeared in 1976 in two simultaneous outbreaks. ${ }^{44}$ EVD is caused by Ebola viruses (EBOV), single-strand RNA viruses of the family Filoviridae. ${ }^{78}$ There are about five species of EBOV, namely Zaire, Bundibugyo, Sudan, Reston and Tai Forest. Although the fatality rate varies from specie to specie of EVD, it is in the range of 50 $90 \%{ }^{44,104}$ The chronology of previous Ebola virus disease outbreaks and the actual fatality rate can be found in the WHO recent reports. ${ }^{119}$ EBOV infects its host cell by attaching to the receptors through the GP glycoprotein and getting endocytosed in host vesicles. ${ }^{44}$ The C-type lectins DCSIGN and DC-SIGNR is pivotal in the process as they bind to Ebola glycoproteins. ${ }^{44}$ The entry pathway of EBOV into host cell, the binding to cell-surface receptors, the slashing of the viral GP1 protein into N-terminal fragment Ebola within the endosome, and the digestion of cathepsin B into GP2 are illustrated in Fig. 7. The laboratory 


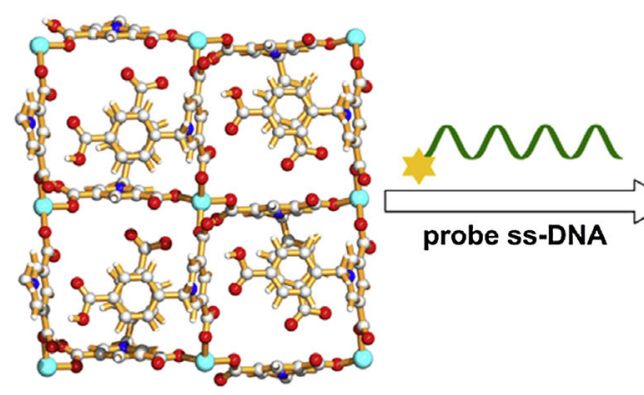

compound 2

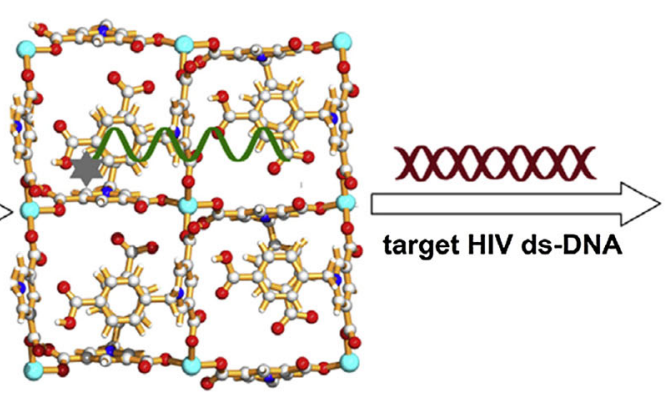

Fluorescence Quenching

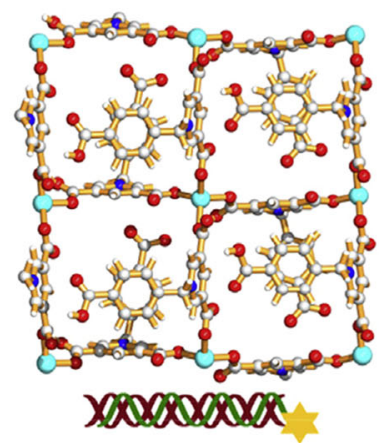

Fluorescence Recovery

FIGURE 6. Proposed mechanism for the detection of target HIV ds-DNA sequences based on a fluorescent biosensor formed from compound 2 and fluorophore-labeled probe ss-DNA. Reproduced with permission from Zhao et al. ${ }^{139}$. (C) 2016 Published by Elsevier B.V.

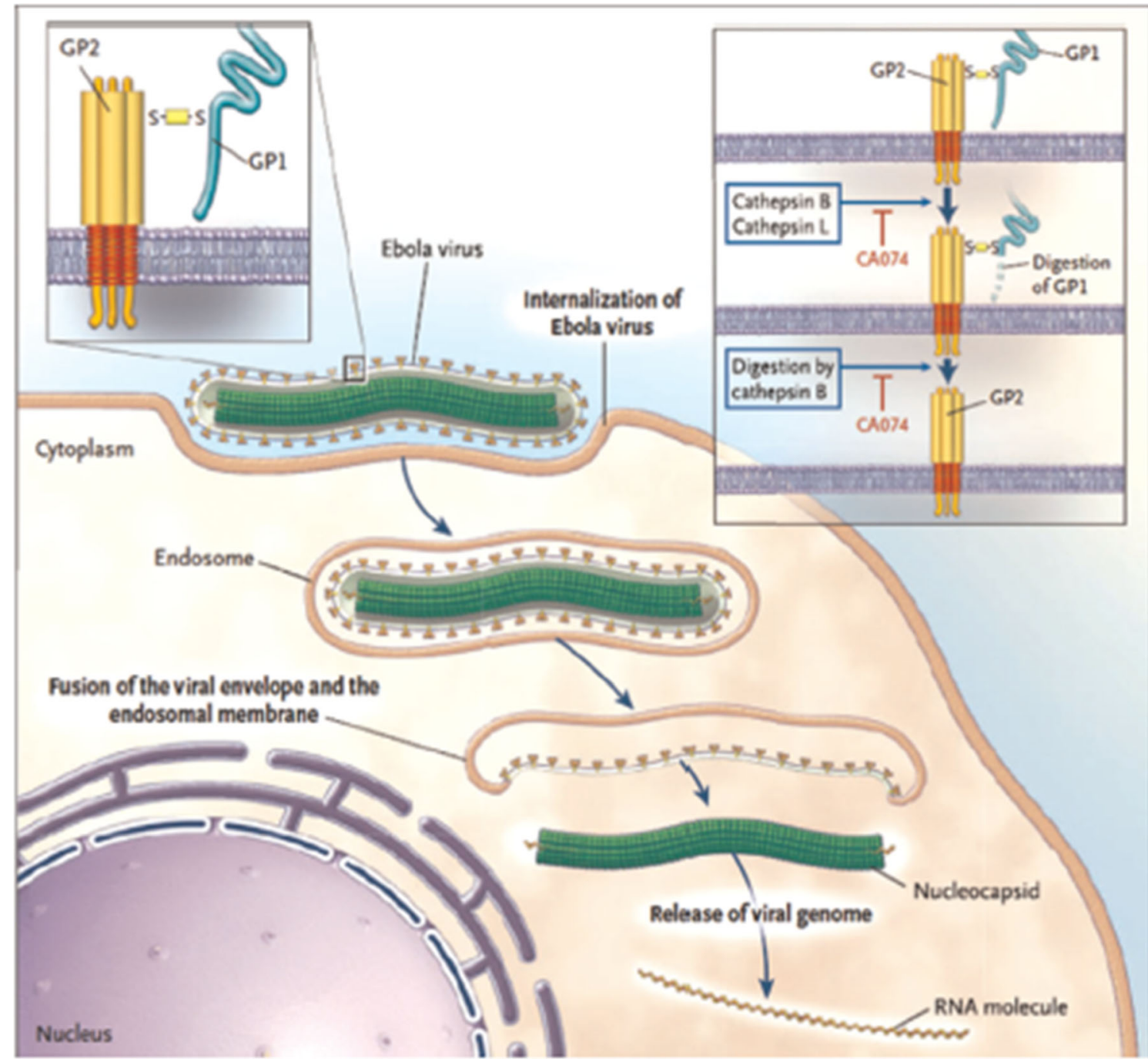

FIGURE 7. Illustration of the entry pathway of Ebola Virus into host cell ${ }^{44}$. The process begins with the EBOV getting attached to the cell surface receptors and internalizing in the endosome. ${ }^{44,78,104,118}$ In the endosome, the endosomal proteases (cathepsin B and cathepsin L) fragment the viral GP1 protein into N-terminal 44,77,103. Cathepsin B thereafter digests it into GP2 that helps in the fusion of the viral envelope and the endosomal membrane. ${ }^{44,78,104}$ The viral genome is then release into the cytoplasm. ${ }^{44,78,104}$ Upon release, the proteolysis of GP1 is inhibited by CA074 ${ }^{44,78,104}$ paving way for the progression of the infection. The figure was reproduced with permission from Kaushik et al. ${ }^{44}$ (C) 2015 Elsevier B.V. 
diagnosis of EBOV includes polymerase chain reaction, enzyme-linked immunosorbent assay (ELISA), antigen ELISA, immunohistochemistry, fluorescence assay, electron microscopy, indirect immunofluorescence assay (IFA), immuno-blot (western blot), biosensors SPR, QCM, optical, and DNA-based fluorescence nanobarcodes methodology. ${ }^{19,44,104}$

Yang et al. ${ }^{130}$ became the first to use MOFs in the detection of EBOV and this was right after the 2014 outbreak in Sudan. Yang and co-workers developed a water-stable three-dimensional $\mathrm{Cu}$-based metal-organic framework $\left[\mathrm{Cu}_{3}(\mathrm{Cmdcp})_{2}(\mathrm{dps})_{4} \cdot\left(\mathrm{H}_{2} \mathrm{O}\right)_{4}\left(\mathrm{SO}_{4}\right)\right]_{\mathrm{n}}$ (where $\mathrm{H}_{3} \mathrm{CmdcpBr}=\mathrm{N}$ carboxymethyl-3,5-dicarboxylpyridinium bromide; dps $=4,4^{\prime}$-dipyridyl sulphide) for the detection of the Sudan Ebola virus (SUDV) RNA sequences. ${ }^{130}$ The MOF exhibited unique pore shapes with aromatic rings, positively charged pyridinium and unsaturated $\mathrm{Cu}$ (II) cation centers, free carboxylates, tessellating $\mathrm{H}_{2} \mathrm{O}$, and coordinating $\mathrm{SO}_{4}{ }^{2-}$ on the pore surface. To investigate the selective detection of the Sudan virus RNA sequences, the authors studied the interaction of the synthesized MOF with carboxyfluorescein (FAM)-labeled probe ss-DNA, 5'-FAMTTAAAAAGTTTGTCCTCATC-3' (P-DNA-2), a complementary sequence of SUDV RNA. ${ }^{130}$ It was found that, upon addition of the MOF, the fluorescence intensity of PDNA-2 decreased significantly (Fig. 8) with quenching efficiency $76 \%$ and the saturation concentration of the P-DNA was found to be $30 \mu \mathrm{M}$. The authors proposed that the interaction of $\left[\mathrm{Cu}_{3}(\mathrm{Cmdcp})_{2}(\mathrm{dps})_{4} \cdot\left(\mathrm{H}_{2} \mathrm{O}\right)_{4}\left(\mathrm{SO}_{4}\right)\right]_{\mathrm{n}}$ with P-DNA-2 was through electrostatic, $\pi$-stacking, and/or hydrogen-bonding interactions that resulted in the formation of a noncovalent complex, P-DNA-2@1 $1^{121}$ that quenched the fluorescence of FAM through a photoinduced electron-transfer process. The P-DNA2@1 system was deemed effective fluorescent sensor for Sudan virus RNA sequence with detection limits of $73 \mathrm{pM}$.

In a subsequent work attempting to further explore and expand the scope of application of MOFs in Ebola virus detection, Yang and co-researchers reacted $\mathrm{La}(-$ $\left.\mathrm{NO}_{3}\right)_{3} \cdot 6 \mathrm{H}_{2} \mathrm{O}$ with the polar, tritopic quaternized carboxylate ligands N-carboxymethyl-3,5dicarboxylpyridinium bromide and N-(4-carboxybenzyl)-3,5-dicarboxylpyridinium bromide to obtain two water-stable metal-organic frameworks (MOFs) of $\left\{\left[\mathrm{La}_{4}(\mathrm{Cmdcp})_{6}\left(\mathrm{H}_{2} \mathrm{O}\right)_{9}\right]\right\}_{\mathrm{n}} \quad(\mathbf{1}, \quad 3 \mathrm{D}) \quad$ and $\left\{\left[\mathrm{La}_{2}(\mathrm{Cbdcp})_{3}\left(\mathrm{H}_{2} \mathrm{O}\right)_{10}\right]\right\}$ n $(2,2 \mathrm{D}){ }^{132}$ The 3D structure of MOF 1 and the 2D plane structure of MOF 2 are shown in Fig. 8. Similar to their previous work, ${ }^{130}$ the interaction of MOFs 1 and $\mathbf{2}$ with FAM-labelled PDNA 5'-FAMTTAAAAAGTTTGTCCTCATC-3', a complementary sequence of SUDV RNA was studied. It was found that MOFs $\mathbf{1}$ and $\mathbf{2}$ quenched the pho-

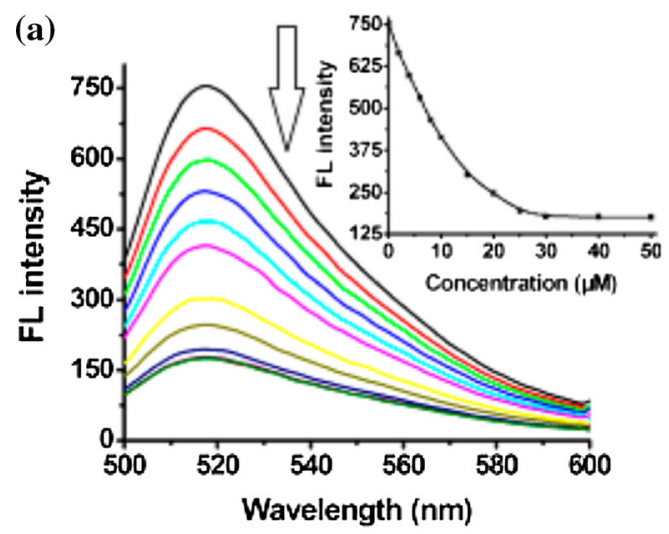

(b)

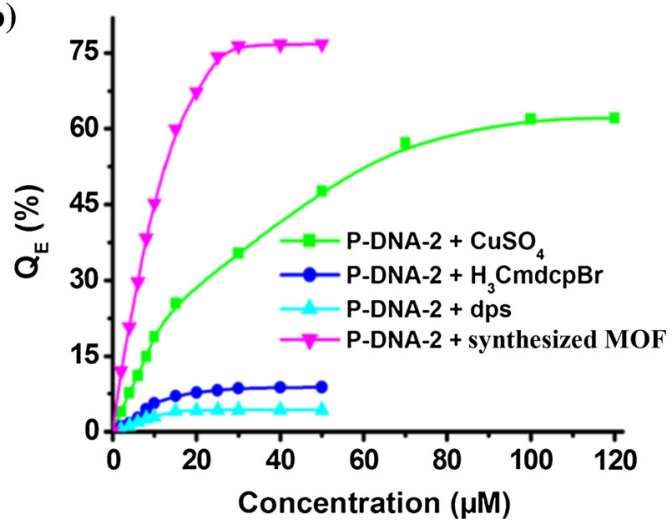

FIGURE 8. (a) Fluorescence spectra of P-DNA-2 (50 nM) incubated with Yang et al. ${ }^{129}$ synthesized MOF of varying concentrations at room temperature. Insets: plots of fluorescence intensity at $518 \mathrm{~nm}$ versus the concentrations of the MOF. (b) Fluorescence quenching efficiency of P-DNA-2 $(50 \mathrm{nM})$ by the prepared MOF, dps, $\mathrm{H}_{3} \mathrm{CmdcpBr}$, and $\mathrm{CuSO}_{4}$ of different concentrations in $100 \mathrm{nM}$ Tris- $\mathrm{HCl}$ buffer $(\mathrm{pH}$ 7.4) at room temperature. Adapted with slight modification from Yang et al. ${ }^{129}$ (C) 2015 American Chemical Society.

toluminescence of the P-DNA due to the formation of P-DNA@1 and P-DNA@2 systems. The quenching efficiencies of $\mathbf{1}$ and $\mathbf{2}$ to P-DNA were reported as 70.2 \pm 5.3 and $57.3 \pm 5.3 \%$, with saturated concentrations of 45 and $40 \mu \mathrm{M}$, respectively. The authors attributed the higher quenching efficiency of MOF 1 in comparison to MOF 2 to the exposure of positively charged quaternary ammonium centers at the edge of the surface area of 1 that provided a stronger electrostatic interaction with P-DNA.

A water-stable metal-organic framework of a zwitterionic carboxylate with dysprosium ${ }^{90}$ and a 3D metal-organic framework (MOF) of $\{[\mathrm{Cu}(\mathrm{Cmdcp})(-$ phen $\left.\left.)\left(\mathrm{H}_{2} \mathrm{O}\right)\right]_{2} \cdot 9 \mathrm{H}_{2} \mathrm{O}\right\} \mathrm{n}$ (phen $=$ phenanthroline $)^{92}$ have also been reported as sensitive and selective fluorescence sensor for the detection of Ebola virus 
Sensing of Zika Virus and Dengue Virus RNA Sequence

Zika and Dengue are mosquito-borne flavivirus. ${ }^{116,117}$ Zika virus (ZIKU) was first identified in Uganda in 1947 in monkeys and later in humans in 1952 in Uganda and the United Republic of Tanzania. ${ }^{116}$ Beside Africa, ZIKU disease outbreaks have been recorded in Asia, the Pacific, and the Americas. ${ }^{116}$ Dengue virus (DENV) is prevalent in the tropical and sub-tropical climates worldwide, mostly in urban and semi-urban areas. There are four DENV serotypes (DENV-1, DENV-2, DENV-3 and DENV-4), implying that it is possible to be infected four times. ${ }^{117}$ Presently, the diagnoses of DENV and ZIKV are based on virus isolation cultures, Enzyme-linked immunosorbent assay (ELISA), genomic RNA detection using Polymerase Chain Reaction (PCR), and fluorescent biosensor. ${ }^{57}$ As earlier mentioned, the fluorescent biosensing technology is gaining attention in the detection of virus nucleic acids because of the advantages of high sensitivity and rapid response time. . $^{57,60,105,111}$

Xie et al. ${ }^{124}$ successfully applied a three-dimensional Cu-based zwitterionic MOF, $[\mathrm{Cu}($ Dcbcp)(bpe) $] \mathrm{n}$ (1, Dcbcp $=\mathrm{N}-(3,5$-dicarboxylbenzyl)-(3-carboxyl) pyridinium, bpe $=1,2$-bis(4-pyridyl)ethylene), for simultaneous detection of ZIKV and DENV RNA sequences. The detection limits for ZIKV were $192 \mathrm{pM}$ and $121 \mathrm{pM}$ for single and synchronous fluorescence analysis respectively. For DENV, single and synchronous fluorescence analysis recorded 332 and $184 \mathrm{pM}$ detection limits respectively. The MOF so synthesized and characterized could form electrostatic, $\pi$ stacking and/or hydrogen bonding interactions with two different fluorophore-labeled DNA probes which created two sensing systems used as fluorescent sensing platforms for the viruses' detection. ${ }^{124}$ The single and synchronous fluorescence analysis recorded high selectivity and sensitivity. There was less interference with other mismatched RNA sequences. The authors reported that the sensing system showed potential application in the diagnosis of other virus associated infectious diseases which have similar clinical manifestations. ${ }^{124}$

\section{Sensing of Thrombin}

The MOF $\mathrm{Cu}\left(\mathrm{H}_{2}\right.$ dtoa $)$ had also been used to target thrombin. ${ }^{80,144}$ Thrombin is an endogenous protein or natural enzymes involved in the coagulation cascade, where it has a key role in the formation of fibrin clots by converting fibrinogen to fibrin. ${ }^{53}$ The same assay principle for HIV-1 U5 long terminal repeat DNA sequence was applied but with detection limit of 1.3 and 5-100 $\mathrm{nM}$ linear range. The sensor system was highly sensitive and selective as well and there was no effect on lysome bovine serum albumin and human IgG enzymes on signal. ${ }^{80,144}$ The fluorescence spectra of the FAM-labeled probe DNA $2-\mathrm{Cu}\left(\mathrm{H}_{2}\right.$ dtoa $)$ in the presence of different concentrations of thrombin is presented in Fig. $5 b$.

\section{DETECTION ASSAYS RELEVANT TO SARS-COV-2 AND COVID-19 DIAGNOSIS}

The detection assays relevant to COVID-19 diagnostic testing and screening are categorized based on detection targets: (i) nucleic acid tests: which detects the presence of viral ribonucleic acids (RNA) using amplification steps based on reverse transcriptase polymerase chain reactions (RT-PCR); (ii) antigen tests: which detect the presence of a viral antigen as part of a surface protein; and (iii) antibody tests: which detect the presence of the antibodies such as immunoglobulin $\mathrm{M}$ (IgM) and $\operatorname{IgG}$ generated against the severe acute respiratory coronavirus-2 (SARSCOV-2). ${ }^{1,62}$

In any case, enzyme-linked immunosorbent assays (ELISA), lateral flow assays (LFA) and chemoluminescence assays (CLIA) are the three most used assays. Besides, virus neutralisation tests and whole genome sequencing may be used to specifically detect neutralising antibodies and determine the sequence of the SARS-CoV-2 virus respectively. LFA is used for testing pregnancy and ovulation at home. It usage is simple, equipment-free hence cost-effective, and rapid thus very essential in biosensing and nanotechnology. ${ }^{47,76,81,85}$ In addition to the understanding of the assays, the diagnostic specimens are important factors to consider. Data comparing the accuracy of test methods suggest that test sensitivity may vary by type of specimen. ${ }^{1,55}$ Specimen for SARS-CoV-2 diagnostic tests can be taken from the upper (nasopharyngeal/ oropharyngeal swabs, nasal aspirate, nasal wash or saliva) or lower (sputum or tracheal aspirate or bronchoalveolar lavage) respiratory tracts. ${ }^{84}$ According to Yang et al., ${ }^{133}$ the most accurate sample for the diagnosis of SARS-CoV-2 is sputum, followed by nasal swabs and throat swabs.

\section{CURRENT BIOSENSING TECHNIQUES FOCUSED ON COVID-19 DIAGNOSIS}

The technology behind testing is biosensing. ${ }^{22,81} \mathrm{~A}$ biosensor is an analytical device which detect biological and biochemical component by employing biomimetic elements or biologically derived materials (nucleic acids, antibodies, antigen, enzymes, orga- 
TABLE 2. Current biosensing techniques focused on COVID-19 diagnosis.

\begin{tabular}{|c|c|c|c|c|}
\hline S. no. & Method & Read out time & Sensitivity/Specificity & References \\
\hline 1 & RT-qPCR & $4 \mathrm{~h}$ & $71 \% / \mathrm{NA}$ & 29,115 \\
\hline 2 & RT-digital PCR & & $90 \% / 100 \%$ & $71,110,127$ \\
\hline 3 & MNPs based RT-qPCR & $30 \mathrm{~min}$ & NA & 43,141 \\
\hline 4 & LAMP-based colorimetric method & $20-30 \mathrm{~min}$ & $97.6 \%$ & 107,136 \\
\hline 5 & CT Scan & NA & $97 \% / 25 \%$ & $2,87,108$ \\
\hline 6 & LFICS-Au NPs colloid (IgM + IgG) & $15 \mathrm{~min}$ & $88.66 \% / 90.63 \%$ & 20,61 \\
\hline 7 & ELISA (IgM + IgG) & $2 \mathrm{~h}$ & $87.3 \% / 100 \%$ & 123 \\
\hline 8 & Chemiluminescence (total Ab)/Automated & NA & $86.9 \% / 99.2 \%$ & 51,122 \\
\hline 9 & CRISPR-based assay & $30-40 \mathrm{~min}$ & $95 \% / 100 \%$ & 9,34 \\
\hline
\end{tabular}

LAMP Loop mediated isothermal amplification, LFICS lateral flow immunochromatographic strip, ELISA Enzyme-linked immunosorbent assay, $A b$ antibody, CRISPR clustered regularly interspaced short palindromic repeats.

(a)

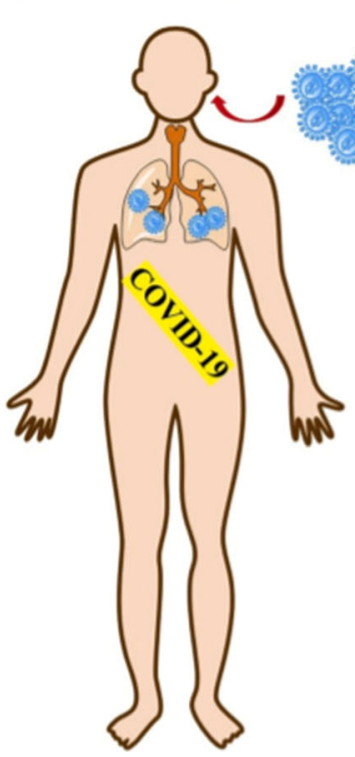

(b) SARS-CoV-2
(environment)

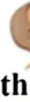

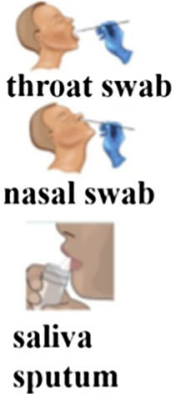

blood

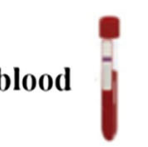

(d)

(e)

FIGURE 9. Schematic diagram of current diagnostic methods and potential portable biosensors for COVID-19. (a) A human being infected with SARS-CoV-2. (b) Sampling from suspected cases or patients and common specimens. (c) Biomarkers and other biochemical indicators for diagnosis of COVID-19. (d) Current detection methods to corresponding biomarkers or indicators. (e) Potential ultrasensitive biosensors, especially EC biosensor and SERS-based biosensors, for virus antigens detection. Reproduced with permission from Cui and Zhou. ${ }^{20}$ (C) 2020 Elsevier B.V.

nelles, tissues, microorganisms etc.) that interact with, bind with, or recognize the analyte under study. ${ }^{7}$ The detector or transducer makes use of optical, electrochemical, electrochemiluminescence and piezoelectric principles to transform one signal into another for easy measurement and quantification. ${ }^{7}$ The biosensing techniques for SARS-COV-2 basically employ nucleic acids/DNA and antibody/antigen biomimetic components or biologically derived materials. ${ }^{94}$ The methods available in literature for COVID-19 testing are presented in Table 2 and the current diagnostic methods and potential portable biosensors for COVID-19 demonstrated diagrammatically in Fig. 9.
In all the methods presented, polymerase chain reaction (PCR)-based test methods are the most utilized. PCR involves amplification of RNA of the virus to produce a sensitive and selective detection. The reverse transcriptase polymerase chain reaction (RTPCR) is currently the standard reference method for COVID-19 diagnosis. ${ }^{6,28}$ However, there are so many limitations associated with the method ${ }^{6}$ :

1. Rapidity: PCR-based methods do not offer the rapidity required in a pandemic outbreak as results may take from four hours up to three days.

2. Skill set: Highly skilled personnel are required to perform the tests.

3. Sensitivity and Selectivity: Standard PCR methods 
may be less sensitive thereby producing false negative results in COVID-19 patients with unclear clinical symptoms ${ }^{2,81}$

4. Flexibility: PCR's flexibility of scaling up for other nucleic acids in an easy and rapid manner is limited due to amplification of spurious nucleic acid contaminations. ${ }^{5,6}$

5. Sample handling: Genetic material may be denatured during handling and transportation since PCR samples require specialized handling, leading to false negatives.

6. Sample Preparation: PCR analysis requires preparation of the number of tests and the extraction kits. Shortage of the test kits may hamper efforts to ramp up COVID-19 testing ${ }^{81}$

7. Discrepancy in Results: The consistency among results may be affected by the quality of reagents utilized by different PCR kit manufacturers.

In what seems to be a good news, there is a method called Clustered Regularly Interspaced Short Palindromic Repeat (CRISPR) mainly employed in gene editing, which is believed to be promising in terms of rapidity, affordability, easy usage, high sensitivity and selectivity in quantifying nucleic acids in low resource setting. ${ }^{9}$ However, the versatility of CRISPR is affected since it still uses a target amplification such as loop-mediated isothermal amplification (LAMP) and recombinase polymerase amplification (RPA) which requires different primers and probes for each target. ${ }^{6,9}$ This has led to the introduction of so many versions of CRISPR such as CRISPR-chip for electrical detection of genetic mutations using Cas9 (CRISPR-Cas9), ${ }^{35}$ electrochemical CRISPR-biosensor for microRNA using Cas13a (CRISPR-Cas13a), ${ }^{10}$ custom CRISPRCas12a/gRNA complex ${ }^{40}$ etc., leading to discrepancies in operations and results which in turns delays or complicate the nature of diagnosis required in a pandemic outbreak. In view of the aforementioned, the biosensing community is urged to create a more robust and versatile system for solving diagnostic problem associated with the current and future pandemic outbreaks.

\section{PROSPECTIVE VIEW OF MOFS AS BIOSENSING MATERIALS FOR COVID-19}

At present, the reverse transcription polymerase chain reaction (RT-PCR) remains the recommended laboratory diagnostic method for COVID-19. ${ }^{31,106}$ However, there are reports of a number of RT-PCR false-negative results on confirmed infection cases. ${ }^{91,125}$ It is a fact that a single negative PCR result does not rule out COVID-19 infection and the culture currently is two negative PCR results. ${ }^{31,106}$ In a recent study of 167 COVID-19 infection patients by Xie et al., ${ }^{125}$ five patients with positive chest computed tomography (CT) received false-negative COVID-19 infection after RT-PCR test. Repeated swab tests on the five patients confirmed the patients as positive to COVID-19. More so, the current RT-PCR-based detection techniques require high manpower and long processing time. ${ }^{125}$ Other diagnostic techniques like the CT scan and culture methods are not suitable for fast-response detection and real-time analysis. ${ }^{134}$ Hence, it is imperative that scientists begin to think in other directions. Despite the roll-out of COVID-19 vaccines, the virus might not disappear with a brink of eyes. As earlier mentioned, MOFs possess outstanding properties that endeared them for the development of biosensors. Besides, there are proven cases where MOFs have been used in detection of viruses (HIV, Ebola, Zika, Dengue, etc.) and infectious diseases. ${ }^{58,92,121,130}$ The high specificity and selectivity of MOFs towards the detection of other viruses and diseases as presented in Section 4 should also be the motivation for the development of MOFs biosensors for COVID-19 detection. This could be a pointer to the huge potentials of MOFs in the fight against SARS outbreaks.

Advantages of MOFs as a Potential Biosensor for SARS-COV-2 Nucleic Acids, Antigens and Antibody Assay

\section{Nucleic Acids Detection}

MOF possesses a unique fluorescence quenching/ recovery with continued decline of fluorescence intensity compared to the traditional fluorescence nanoquenchers such as gold nanotubes, graphenes, graphene oxides etc. ${ }^{42,59,77,89}$ This makes it promising in detection of SARS-CoV-2 viral RNA (nucleic acid). The fluorophore-labeled probes could be adsorbed on MOF through various interactions including electrostatic interactions, hydrogen bonding, and $\pi-\pi$ stacking with negatively charged aromatic nucleic acid sequences similar to those presented in Sections 4.1, 4.2 and 4.3 for HIV-1 ssDNA, SUDV and HIV ssDNA. The fluorescence of dyes on probes could be quenched by metal ions, such as $\mathrm{Cu}^{2+}, \mathrm{Fe}^{3+}, \mathrm{Zn}^{2+}$, $\mathrm{Dy}^{3+}$ or coplanar structure via the process of fluorescence resonance energy transfer (FRET). ${ }^{12,113}$ The specific hybridization of probe DNA (P-DNA) with target virus-related nucleic acids sequences could form stable rigid double or triple-stranded DNA structures and would be released from the surface of MOF due to their low affinity toward nanomaterials, leading to efficient recovery of fluorescence. ${ }^{26,41,112,113}$ The possible nucleic acid detection mechanism and quenching/ 
(a)
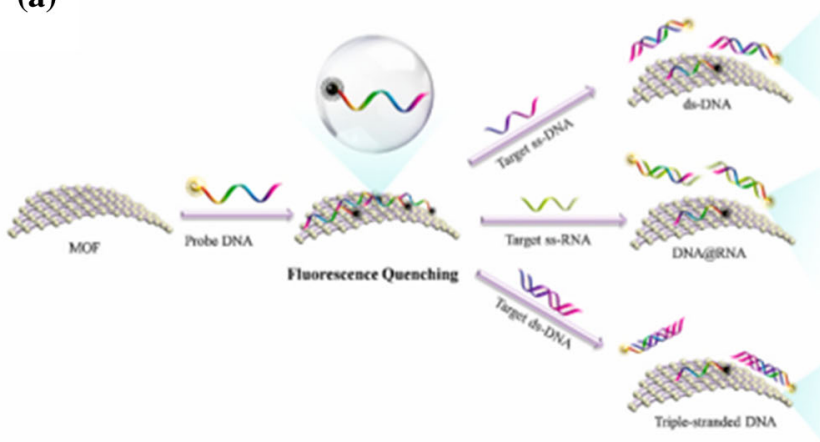

Fworeseence Recovery
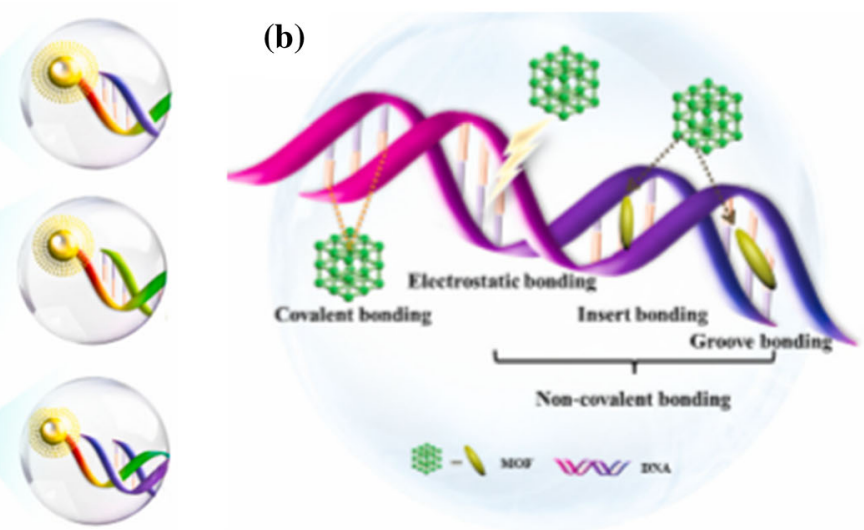

(c)
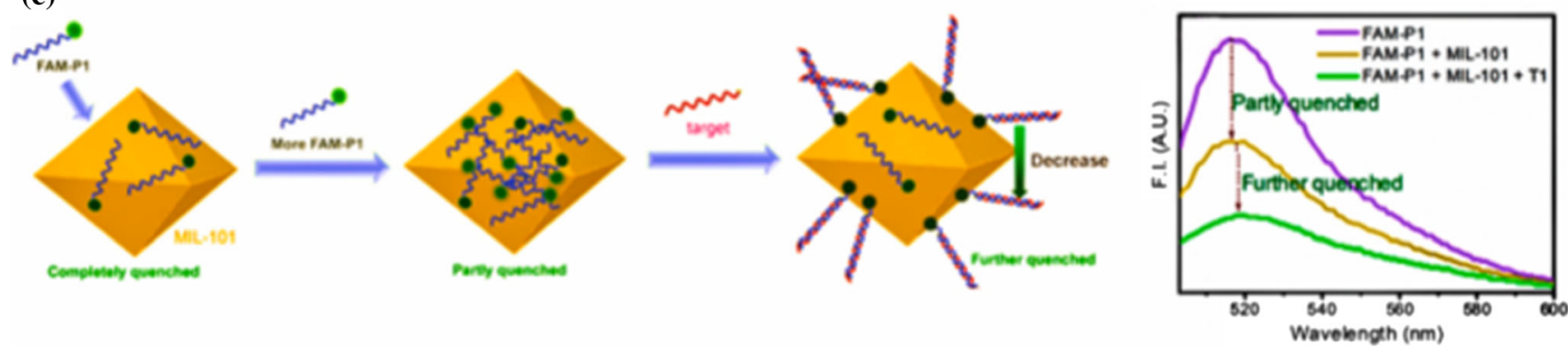

FIGURE 10. (a) Schematic diagram of the viral nucleic acid detection mechanisms (b) The linking methods of coordination polymer in MOF with DNA. (c) Fluorescence quenching properties of MIL-101 toward FAM-labeled DNA. Reproduced with permission from Wang et al. ${ }^{112}$ (C) 2017, American Chemical Society.

recovery processes are depicted in Fig. 10. Again, the abundant functional groups and positively charged metal ions in MOF may provide various interactions, such as electrostatic interactions, hydrogen bonding, and $\pi-\pi$ stacking for adsorption of fluorophore-labeled probes as presented in Fig. 11.

\section{Antigen Detection}

With MOF-based detection platform, many viruses such as Avian leukosis virus (ALV), ${ }^{66}$ Japanese encephalitis virus (JEV), ${ }^{129} \mathrm{HIV},{ }^{25}$ hepatitis A virus (HAV) ${ }^{73}$ have been effectively detected by antigen detection methods which are primarily based on the ELISA and molecular imprinting technology. Molecular imprinting technology is antigen detection technology that possesses remarkable advantages of brief and inexpensive preparation and prospective selectivity. ${ }^{113}$ The imprinted particles can capture the target virus quickly and show excellent selectivity for viruses because the imprinted sites are generated during imprinting. ${ }^{73}$ Although earlier approaches to viruses' detection using molecular imprinting faced a challenge of large size viruses of $20-900 \mathrm{~nm}$, this can be overcome by finding an imprinted carrier with sufficient surface area for providing additional imprinting sites. MOF is a typical material with high surface area, which is basically related to its porous structure. For example, MIL-100 (Cr) and MIL-101 (Cr) have a large pore of 2.5-2.9 and 2.9-3.4 nm, respectively. The larger surface area of the MOF can provide more imprinting sites for virus detection, which is beneficial to expand the linear range and improve sensitivity. With the large surface area advantage, other viral antigens detection methods, such as electrochemiluminescent immunosensing, ${ }^{74}$ immunochromatographic assay, ${ }^{68}$ sandwich-immunoassay LSPR chip ${ }^{46}$ may be adopted. Electrochemical immunoassay has many advantages, including good reproducibility, high sensitivity, low cost, fast and accurate analysis, which has attracted widespread attention in virus detection. ${ }^{113}$

\section{Antibody Detection}

MOFs-based fluorescence biosensor for antigen detection has a suitable adsorption capacity for molecular probes which is more conducive to fluorescence recovery compared to similar class of materials, such as single-walled carbon nanotubes (SWCNTs) and grapheme oxides (GO). ${ }^{114}$ Its application in SARS-COV-2 antibody detection will offer a high selectivity which is mainly based on the specific recognition of antibodies and antigens. Wei et al. ${ }^{114}$ developed a Cu-based novel biosensor MOF $\left(\mathrm{H}_{2}\right.$ dtoaCu$)$ for the detection of influenza virus $\mathrm{H}_{5} \mathrm{~N}_{1}$ antibody and the ss-DNA linked with $\mathrm{H}_{5} \mathrm{~N}_{1}$ antigens 


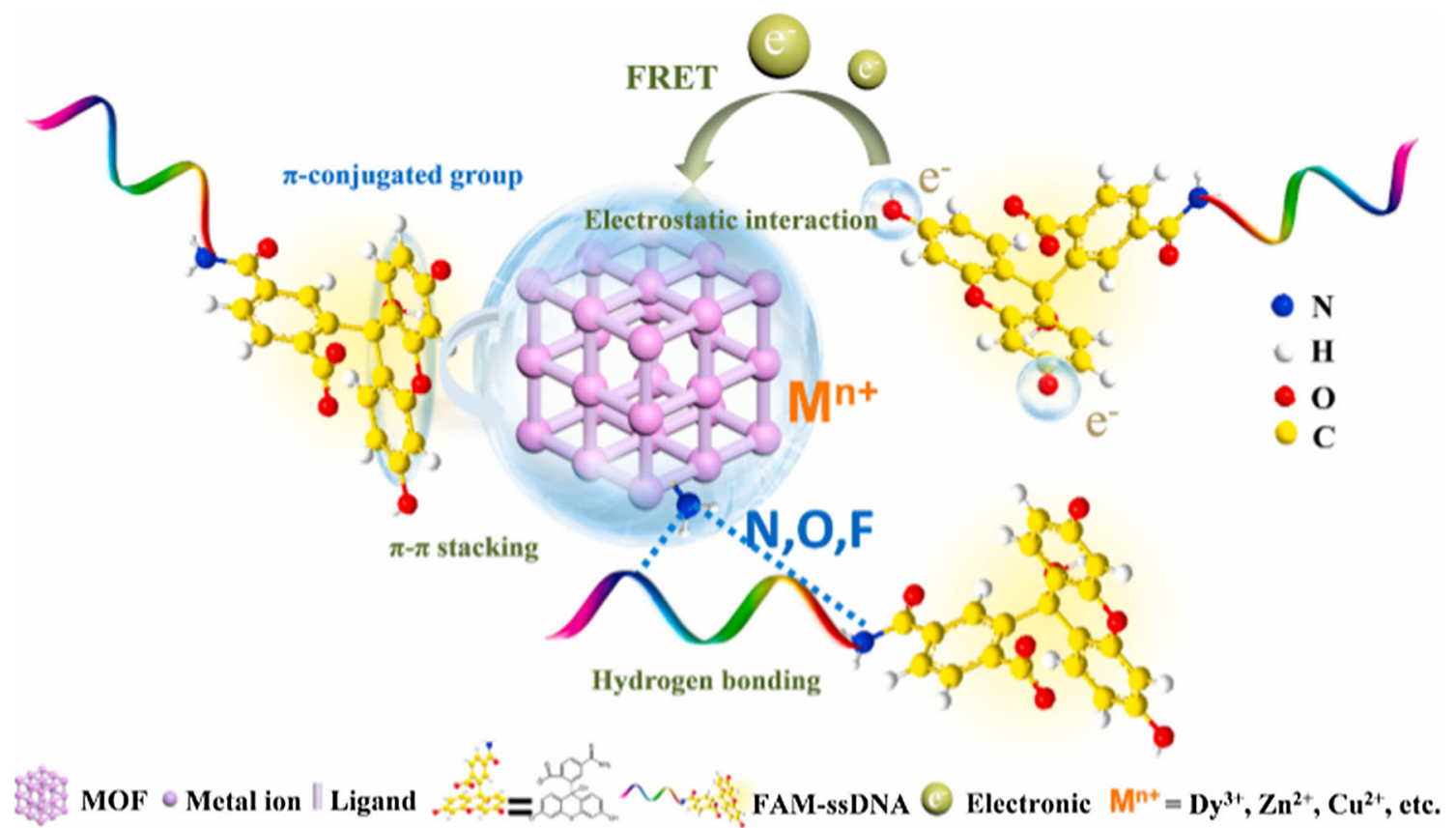

FIGURE 11. The interaction between the MOF and probe DNA (taking FAM-ssDNA as an example). Reproduced with permission from Wang et al. ${ }^{113}$ (C) 2020 American Chemical Society.

and fluorescent dye 5' 6-carboxyfluorescein were adsorbed by the MOF, resulting in the effective quenching of fluorescence making it easy to recover. This was because aromatic compounds (such as FAM) could be less strongly bound to MOF through noncovalent van der Waals interactions, making the fluorescence easier to be recovered compared to GO and SWCNT which is quite difficult. The MOF was proven to be advantageous in terms of sensitivity, rapidity, cracking and stable period's detection, simplicity in operation and cost-effectiveness. ${ }^{114}$ This could be adopted in SARS-COV-2 or similar strands of virus. The composition of the MOFs such as metal ions, functional groups; and properties such as geometry, size, porosity and stability are important factors to consider when developing MOF based biosensors for diagnoses of SARS-COV-2 and similar viruses. Stock and Biswas ${ }^{102}$ and Wang et al. ${ }^{113}$ have presented detailed information on these factors.

\section{Challenges Associated with Incorporating MOFs} in Viral Diagnosis and Steps to Address Them in Future Researches

The major challenges associated with MOF-based viral detection and diagnostic strategies are the detection limit, instability of some MOFs in aqueous medium and complex physiological environments, ${ }^{64,109}$ biological toxicity of some metal ions in the MOFs and complex in vivo environment. ${ }^{14}$ The detection limit of
MOFs ranged from $\mathrm{pM}$ to $\mathrm{nM}$ and is not low enough to detect a low level of viruses in the clinical samples, hence may affect sensitivity. To improve on this, future researches should consider the following (1) designing structures of MOFs with reduced particle sizes to amplify fluorescence signal as well as enhance high quenching efficiency and good selectivity; (2) integrating viral RNA in developing novel biosensors using nanoparticles, such as MOF-derived porous carbon $^{41}$; (3) generating automated ultrasensitive MOFs-based biosensors with high-throughput screening in a large-scale, combining electrochemistry technologies ${ }^{21}$ and high class devices like lab-on-a-chip ${ }^{96}$; (4) combining MOF with metal oxides, metal particles, or carbon materials for electrochemical detection of viruses will be a promising direction since oxide is known to enhance binding ability, biological activity, and sensing performance. ${ }^{101}$

To address the challenge of MOFs instability in aqueous medium and complex physiological environment, water-stable MOFs can be constructed with zwitterionic carboxylate ligands ${ }^{131}$ or zwitterionic thiolate $^{56}$ and some metal ions including $\mathrm{Zn}^{2+110}$ and $\mathrm{Zr}^{4+13}$ Moreover, water-stable MOFs can be obtained by doping metal ions. ${ }^{145}$ For instance, small amounts of second metals such as $\mathrm{Mn}^{2+}, \mathrm{Zn}^{2+}, \mathrm{Mg}^{2+}$ and $\mathrm{Ca}^{2+}$ can be incorporated into metal clusters to enhance the stability of MIL-100 (Fe) moiety. ${ }^{3}$ 
In the case of biological toxicity of some metal ions in the MOFs and in vivo environment, the detection performance and safety of MOF-based biosensing need to be further verified in vivo and some biocompatible metal ions (such as $\mathrm{Fe}^{2+} / \mathrm{Fe}^{3+}, \mathrm{Ni}^{3+}, \mathrm{Zr}^{4+}$, $\mathrm{Mn}^{2+}, \mathrm{Mg}^{2+}, \mathrm{Ca}^{2+}, \mathrm{Zn}^{2+}$ ), or biomaterials (such as liposomal bio-conjugates). Green synthetic routes using Sonochemistry should also be considered. ${ }^{27,75}$ MOFs functional modification with target ligands (viz: aptamers) ${ }^{12,38}$ enhance its functionalities, with detection performances much better than the biosensor platforms based on graphene oxide. ${ }^{26}$

\section{CONCLUSIONS}

The science of biosensors as diagnostic tools is highly promising. Embracing these tools can ensure life-saving decisions on the handling, understanding, and treatment of pandemic strains. As the world continues to be ravaged with COVID-19 pandemic and with the uncertainties surrounding the current COVID-19 diagnosis approaches, this review tends to draw the attention of researchers towards thinking in the direction of metal organic frameworks (MOFs) as a biosensor in COVID-19 pandemic outbreak. The application of MOFs as biosensors in pandemic outbreaks such as Human Immunodeficiency virus, Ebola virus, Zika virus, Dengue virus, and as biosensor for sensing Thrombin have been highlighted. The attractive features of MOFs that endeared them for biosensing applications include the large surface area, tailorable structure, high porosity, tunable size, and versatile functionality. Because COVID-19 pandemic may not disappear anytime soon despite the rolling out of vaccine, early testing and isolation would remain the safest approach and taking proactive steps to utilize MOFs biosensor may be a significant milestone. As a promising potential platform for detecting SARSCoV-2, MOF has the following advantages (1) it can be used as an adsorption and fluorescence quenching platform; (2) MOF with unique structure can be designed using molecular imprinting technology; (3) MOFs can serve as a simple and effective fluorescence anisotropy amplification platform for SARS-COV-2 detection.

\section{CONFLICT OF INTEREST}

The authors declare that they have no known competing financial interests or personal relationships that could have appeared to influence the work reported in this paper.

\section{REFERENCES}

${ }^{1}$ (ECDC), E.C. for D.P. and C. Diagnostic testing and screening for SARS-CoV-2., 2020 [cited 2021 Mar 11]. h ttps://www.ecdc.europa.eu/en/covid-19/latest-evidence/di agnostic-testing.

${ }^{2} \mathrm{Ai}, \mathrm{T}$., et al. Correlation of chest CT and RT-PCR testing for coronavirus disease 2019 (COVID-19) in China: A report of 1014 cases. Radiology 296:E32-E40, 2020. http s://doi.org/10.1148/radiol.2020200642.

${ }^{3}$ AlHaydar, M., H. R. Abid, B. Sunderland, and S. Wang. Multimetal organic frameworks as drug carriers: Aceclofenac as a drug candidate. Drug Des. Dev. Ther. 13:2335, 2019.

${ }^{4}$ American College of Obstetricians and Gynecologists. Routine human immunodeficiency virus screening. Committee opinion No. 596. Obs. Gynecol. 123:1137-1139, 2014.

${ }^{5}$ Bej, A. K., M. H. Mahbubani, R. M. Atlas, and R. K. Salkl. Amplification of nucleic acids by polymerase chain reaction (PCR) and other methods and their applications. Crit. Rev. Biochem. Mol. Biol. 26:301-334, 1991.

${ }^{6}$ Benzigar, M. R., R. Bhattacharjee, M. Baharfar, and G. Liu. Current methods for diagnosis of human coronaviruses: pros and cons. Anal. Bioanal. Chem. 2020. http s://doi.org/10.1007/s00216-020-03046-0.

${ }^{7}$ Bhalla, N., P. Jolly, N. Formisano, and P. Estrela. Introduction to biosensors. Essays Biochem. 60:1-8, 2016.

${ }^{8}$ Boeke, J. D., and K. B. Chapman. Retrotransposition mechanisms. Curr. Opin. Cell Biol. 3:502-507, 1991.

${ }^{9}$ Broughton, J. P., et al. CRISPR-Cas12-based detection of SARS-CoV-2. Nat. Biotechnol. Nature Research 38:870-874, 2020. https://doi.org/10.1038/s41587-020-05 13-4.

${ }^{10}$ Bruch, R., et al. CRISPR/Cas 13a-powered electrochemical microfluidic biosensor for nucleic acid amplificationfree miRNA diagnostics. Adv. Mater. 31:1905311, 2019.

${ }^{11}$ Cai, H., Y. L. Huang, and D. Li. Biological metal-organic frameworks: Structures, host-guest chemistry and bioapplications. Coord. Chem. Rev. 15:207-221, 2019.

${ }^{12}$ Cai, S., J. Yan, H. Xiong, Y. Liu, D. Peng, and Z. Liu. Investigations on the interface of nucleic acid aptamers and binding targets. Analyst. 22:5317-5338, 2018.

${ }^{13}$ Cavka, J. H., et al. A new zirconium inorganic building brick forming metal organic frameworks with exceptional stability. J. Am. Chem. Soc. 130:13850-13851, 2008. http s://doi.org/10.1021/ja8057953.

${ }^{14}$ Chen, G., et al. In vitro toxicity study of a porous iron(III) metal-organic framework. Molecules 24:1211, 2019.

${ }^{15}$ Chen, L., G. Zhang, L. Liu, and Z. Li. Emerging biosensing technologies for improved diagnostics of COVID-19 and future pandemics. Talanta 225:2021.

${ }^{16}$ Chen, M., N. Gan, T. Li, Y. Wang, Q. Xu, and Y. Chen. An electrochemical aptasensor for multiplex antibiotics detection using Y-shaped DNA-based metal ions encoded probes with NMOF substrate and CSRP target-triggered amplification strategy. Anal. Chim. Acta 968:30-39, 2017.

${ }^{17}$ Chen, Y.-A., et al. Fast and effective turn-on paper-based phosphorescence biosensor for detection of glucose in serum. J. Chin. Chem. Soc. 63:424-431, 2016.

${ }^{18}$ Cheng, Y. H., et al. Metal-organic framework-based microfluidic impedance sensor platform for ultrasensitive detection of perfluorooctanesulfonate. ACS Appl. Mater. Interfaces 12:10503-10514, 2020. https://doi.org/10.1021/ acsami.9b22445. 
${ }^{19}$ Coarsey, C. T., N. Esiobu, R. Narayanan, M. Pavlovic, H. Shafiee, and W. Asghar. Strategies in Ebola virus disease (EVD) diagnostics at the point of care. Crit. Rev. Microbiol. 14:779-798, 2017.

${ }^{20}$ Cui, F., and H. S. Zhou. Diagnostic methods and potential portable biosensors for coronavirus disease 2019. Biosens. Bioelectron. 165:112349, 2020.

${ }^{21}$ de Eguilaz, M. R., L. R. Cumba, and R. J. Forster. Electrochemical detection of viruses and antibodies: A mini review. Electrochem. Commun. 22:106762, 2020.

${ }^{22}$ Dincer, C., et al. Disposable sensors in diagnostics, food, and environmental monitoring. Adv. Mater. 31:1806739, 2019.

${ }^{23}$ Divya, S., R. Katz, E. Graeden, D.A. and T.T. Evidence Roundup: Why positive test rates need to fall below 3\% Harvard Global Health Institute. Pandemics. 2020. http s://globalhealth.harvard.edu/evidence-roundup-why-posi tive-test-rates-need-to-fall-below-3/.

${ }^{24}$ Dong, E., H. Du, and L. Gardner. An interactive webbased dashboard to track COVID-19 in real time. Lancet Infect. Dis. 157:533-534, 2020.

${ }^{25} \mathrm{Du}, \mathrm{M}$., et al. Self-assembled fluorescent Ce(III) coordination polymer as ratiometric probe for HIV antigen detection. Anal. Chim. Acta 1084:116-122, 2019.

${ }^{26} \mathrm{Du}, \mathrm{P}$. , et al. Tumor microenvironment and NIR laser dual-responsive release of berberine 9-O-pyrazole alkyl derivative loaded in graphene oxide nanosheets for chemo-photothermal synergetic cancer therapy. J. Mater. Chem. B 8:4046-4055, 2020.

${ }^{27}$ Dunne, M., B. Epp-Ducharme, A. M. Sofias, M. Regenold, D. N. Dubins, and C. Allen. Heat-activated drug delivery increases tumor accumulation of synergistic chemotherapies. J. Control. Release 308:197-208, 2019.

${ }^{28}$ Emery, S. L., et al. Real-time reverse transcription-polymerase chain reaction assay for SARS-associated coronavirus. Emerg. Infect. Dis. 10:311-316, 2004.

${ }^{29}$ Fang, Y., et al. Sensitivity of chest CT for COVID-19: Comparison to RT-PCR. Radiology 2020. https://doi.org/ 10.1148/radiol.2020200432.

${ }^{30}$ Faria, N. R., et al. The early spread and epidemic ignition of HIV-1 in human populations. Science 346:56-61, 2014.

${ }^{31}$ Fauci, A. S., H. C. Lane, and R. R. Redfield. Covid19-Navigating the uncharted. N. Engl. J. Med 382:12681269, 2020.

${ }^{32}$ Gao, F., et al. Origin of HIV-1 in the chimpanzee Pan troglodytes troglodytes. Nature 397:436-441, 1999.

${ }^{33}$ Gao, J., C. Huang, Y. Lin, P. Tong, and L. Zhang. In situ solvothermal synthesis of metal-organic framework coated fiber for highly sensitive solid-phase microextraction of polycyclic aromatic hydrocarbons. J. Chromatogr. A 1436:1-8, 2016.

${ }^{34}$ Habli, Z., S. Saleh, H. Zaraket, and M. L. Khraiche. COVID-19 in-vitro diagnostics: state-of-the-art and challenges for rapid, scalable, and high-accuracy screening. Front. Bioeng. Biotechnol. 8:605702, 2021.

${ }^{35}$ Hajian, R., et al. Detection of unamplified target genes via CRISPR-Cas9 immobilized on a graphene field-effect transistor. Nat. Biomed. Eng. 3:427-437, 2019.

${ }^{36}$ Hao, J.-N., and B. Yan. Recyclable lanthanide-functionalized MOF hybrids to determine hippuric acid in urine as biological indices of toluene exposure. Chem. Commun. 00:1-3, 2013

${ }^{37}$ Hasell, J., et al. A cross-country database of COVID-19 testing. Sci. Data 7:1-7, 2020. https://doi.org/10.1038/s41 597-020-00688-8.
${ }^{38} \mathrm{He}$, F., et al. Aptamer-based targeted drug delivery systems: Current potential and challenges. Curr. Med. Chem. 27:2189-2219, 2018.

${ }^{39}$ Ho, M. L., et al. The construction of glucose biosensor based on crystalline iridium(III)-containing coordination polymers with fiber-optic detection. Sens. Actuators B Chem. 190:479-485, 2014.

${ }^{40}$ Huang, Z., et al. Ultra-sensitive and high-throughput CRISPR-p owered COVID-19 diagnosis. Biosens. Bioelectron. 164:2020

${ }^{41} \mathrm{Jia}, \mathrm{Z}$., et al. $\mathrm{NiCo}_{2} \mathrm{O}_{4}$ spinel embedded with carbon nanotubes derived from bimetallic NiCo metal-organic framework for the ultrasensitive detection of human immune deficiency virus-1 gene. Biosens. Bioelectron. 133:55-63, 2019.

${ }^{42}$ Joshi, S. R., A. Sharma, G. H. Kim, and J. Jang. Low cost synthesis of reduced graphene oxide using biopolymer for influenza virus sensor. Mater. Sci. Eng. C 108:110465, 2020.

${ }^{43}$ Kailasa, S. K., et al. An overview of molecular biology and nanotechnology based analytical methods for the detection of SARS-CoV-2: promising biotools for the rapid diagnosis of COVID-19. Analyst 146:1489-1513, 2021.

${ }^{44}$ Kaushik, A., S. Tiwari, R. DevJayant, A. Marty, and M. Nair. Towards detection and diagnosis of Ebola virus disease at point-of-care. Biosens. Bioelectron. 18:254-272, 2016.

${ }^{45}$ Kelly-Cirino, C. D., et al. Importance of diagnostics in epidemic and pandemic preparedness. BMJ Glob. Heal. 4:1179, 2019.

${ }^{46} \mathrm{Kim}$, J., et al. Heteroassembled gold nanoparticles with sandwich-immunoassay LSPR chip format for rapid and sensitive detection of hepatitis B virus surface antigen (HBsAg). Biosens. Bioelectron. 107:118-122, 2018.

${ }^{47}$ Koczula, K. M., and A. Gallotta. Lateral flow assays. Essays Biochem. 60:111-120, 2016.

${ }^{48}$ Kotzabasaki, M., and G. E. Froudakis. Review of computer simulations on anti-cancer drug delivery in MOFs. Inorg. Chem. Front. 85:1255-1272, 2018.

${ }^{49}$ Kreno, L. E., J. T. Hupp, and R. P. Van Duyne. Metalorganic framework thin film for enhanced localized surface Plasmon resonance gas sensing. Anal. Chem. 82:80428046, 2010.

${ }^{50}$ Kukkar, D., Vellingiri, K., Kim, K.-H., A. Deep. Recent progress in biological and chemical sensing by luminescent metal-organic frameworks. Sens. Actuators B: Chem. 273:1346-1370, 2018. https://doi.org/10.1016/j.snb.2018.0 6.128 .

${ }^{51}$ Kubo, S., et al. Development of an Automated Chemiluminescence Assay System for Quantitative Measurement of Multiple Anti-SARS-CoV-2 Antibodies. Front. Microbiol. 11:2021.

${ }^{52}$ Kumar, P., A. Deep, A. K. Paul, and L. M. Bharadwaj. Bioconjugation of MOF-5 for molecular sensing. J. Porous Mater. 21:99-104, 2014.

${ }^{53}$ Le Bonniec, B. F. Thrombin Handbook of Proteolytic Enzymes. Amsterdam: Elsevier, pp. 2915-2932, 2013.

${ }^{54}$ Lee, Y. J., Y. J. Chang, D. J. Lee, and J. P. Hsu. Water stable metal-organic framework as adsorbent from aqueous solution: A mini-review. J. Taiwan Inst. Chem. Eng. 19:176-183, 2018.

${ }^{55}$ Leeflang, M. M. G., A. W. S. Rutjes, J. B. Reitsma, L. Hooft, and P. M. M. Bossuyt. Variation of a test's sen- 
sitivity and specificity with disease prevalence. CMAJ 185:E537, 2013

${ }^{56} \mathrm{Li}$, F. L., et al. Counterintuitive solid-state syntheses of indium-thiolate-phen cations as efficient and selective fluorescent biosensors for HIV-1 ds-DNA and sudan ebolavirus RNA sequences. ChemistrySelect 1:2979-2987, 2016

${ }^{57}$ Li, J., K. Yang, Z. Wu, X. Li, and Q. Duan. Nitrogendoped porous carbon-based fluorescence sensor for the detection of ZIKV RNA sequences: Fluorescence image analysis. Talanta 205:1, 2019.

${ }^{58} \mathrm{Li}$, J., K. Yang, Z. Wu, X. Li, and Q. Duan. Nitrogendoped porous carbon-based fluorescence sensor for the detection of ZIKV RNA sequences: fluorescence image analysis. Talanta 2019. https://doi.org/10.1016/j.talanta.2 019.06.091.

${ }^{59} \mathrm{Li}$, Y., et al. Aptamers-based sensing strategy for $17 \beta$ estradiol through fluorescence resonance energy transfer between oppositely charged CdTe quantum dots and gold nanoparticles. J. Nanosci. Nanotechnol. 18:1517-1527, 2017.

${ }^{60}$ Li, Y., A. Guo, L. Chang, W.-J. Li, and W.-J. Ruan. Luminescent metal-organic-framework-based label-free assay of polyphenol oxidase with fluorescent scan. Chem. A Eur. J. 23:6562-6569, 2017.

${ }^{61}$ Li, Z., Y. Yi, X. Luo, N. Xiong, Y. Liu, S. Li, R. Sun, Y. Wang, and B. Hu. Development and clinical application of A rapid IgM-IgG combined antibody test for SARSCoV-2 infection diagnosis. J. Med. Virol. 11:1-7, 2020.

${ }^{62} \mathrm{Li}, \mathrm{Z}$., et al. Development and clinical application of a rapid IgM-IgG combined antibody test for SARS-CoV-2 infection diagnosis. J. Med. Virol. 92:1518-1524, 2020.

${ }^{63}$ Lian, X., T. Miao, X. Xu, C. Zhang, and B. Yan. Eu3+ functionalized Sc-MOFs: Turn-on fluorescent switch for ppb-level biomarker of plastic pollutant polystyrene in serum and urine and on-site detection by smartphone. Biosens. Bioelectron. 97:299-304, 2017.

${ }^{64}$ Lin, S. X., et al. Effective loading of cisplatin into a nanoscale UiO-66 metal-organic framework with preformed defects. Dalt. Trans. 48:5308-5314, 2019.

${ }^{65}$ Liu, B., K. Vellingiri, S.-H. Jo, P. Kumar, Y. S. Ok, and K.-H. Kim. Recent advances in controlled modification of the size and morphology of metal-organic frameworks. Nano Res. 11:4441-4467, 2018. https://doi.org/10.1007/s1 2274-018-2039-3.

${ }^{66}$ Liu, C., et al. An electrochemical immunosensor based on an etched zeolitic imidazolate framework for detection of avian leukosis virus subgroup. J. Microchim. Acta 185:19, 2018. https://doi.org/10.1007/s00604-018-2930-3.

${ }^{67}$ Liu, J., Y. Wang, A. I. Benin, P. Jakubczak, R. R. Willis, and M. D. LeVan. $\mathrm{CO}_{2} / \mathrm{H}_{2} \mathrm{O}$ adsorption equilibrium and rates on metal-organic frameworks: HKUST-1 and $\mathrm{Ni}$ / DOBDC. Langmuir 26:14301-14307, 2010.

${ }^{68}$ Liu, J., Q. Yu, G. Zhao, and W. Dou. A novel immunochromatographic assay using ultramarine blue particles as visible label for quantitative detection of hepatitis B virus surface antigen. Anal. Chim. Acta 1098:140-147, 2020.

${ }^{69}$ Liu, L., Y. Zhou, S. Liu, and M. Xu. The applications of metal-organic frameworks in electrochemical sensors. ChemElectroChem. 14:6-19, 2018.

${ }^{70}$ Liu, X., L. Zhang, and J. Wang. Design strategies for MOF-derived porous functional materials: Preserving surfaces and nurturing pores. J. Mater. 15:440-459, 2021.
${ }^{71}$ Lu, R., J. Wang, M. Li, Y. Wang, J. Dong, and W. Cai. SARS-CoV-2 detection using digital PCR for COVID-19 diagnosis, treatment monitoring and criteria for discharge. medRxiv 2020. https://doi.org/10.1101/2020.03.24. 20042689.

${ }^{72} \mathrm{Lu}, \mathrm{X}$., et al. Response characteristics of bisphenols on a metal-organic framework-based tyrosinase nanosensor. ACS Appl. Mater. Interfaces 8:16533-16539, 2016. http s://doi.org/10.1021/acsami.6b05008.

${ }^{73}$ Luo, L., F. Zhang, C. Chen, and C. Cai. Molecular imprinting resonance light scattering nanoprobes based on $\mathrm{pH}$-responsive metal-organic framework for determination of hepatitis A virus. Microchim. Acta 187:1-8, 2020. https://doi.org/10.1007/s00604-020-4122-1.

${ }^{74} \mathrm{Ma}, \mathrm{H}$., et al. Electrochemiluminescent immunosensing of prostate-specific antigen based on silver nanoparticlesdoped $\mathrm{Pb}(\mathrm{II})$ metal-organic framework. Biosens. Bioelectron. 79:379-385, 2016.

${ }^{75}$ Malfanti, A., et al. Oligo-guanidyl targeted bioconjugates forming rod shaped polyplexes as a new nanoplatform for oligonucleotide delivery. J. Control. Release 310:58-73, 2019.

${ }^{76}$ Marquez, S., and E. Morales-Narváez. Nanoplasmonics in paper-based analytical devices. Front. Bioeng. Biotechnol. 84:69, 2019

${ }^{77}$ Mars, A., M. Hamami, L. Bechnak, D. Patra, and N. Raouafi. Curcumin-graphene quantum dots for dual mode sensing platform: Electrochemical and fluorescence detection of APOe4, responsible of Alzheimer's disease. Anal. Chim. Acta 1036:141-146, 2018.

${ }^{78}$ Marzi, A., and L. Banadyga. Ebola Virus (Filoviridae). In: Encyclopedia of Virology. Amsterdam: Elsevier, pp. 232-244, 2021

${ }^{79}$ Massinga, M., A. Tshangela, S. J. Salyer, J. K. Varma, A. E. O. Ouma, and J. N. Nkengasong. COVID-19 in Africa: the spread and response. Nat. Med. 2020. https://doi.org/ 10.1038/s41591-020-0960-y.

${ }^{80}$ Miller, S. E., M. H. Teplensky, P. Z. Moghadam, and D. Fairen-Jimenez. Metal-organic frameworks as biosensors for luminescence-based detection and imaging. Interface Focus 6:20160027, 2016.

${ }^{81}$ Morales-Narváez, E., and C. Dincer. The impact of biosensing in a pandemic outbreak: COVID-19. Biosens. Bioelectron. 163:112274, 2020.

${ }^{82}$ Mozhgani, S. H., H. A. Kermani, M. Norouzi, M. Arabi, and S. Soltani. Nanotechnology based strategies for HIV1 and HTLV-1 retroviruses gene detection. Heliyon. 15:e04048, 2020.

${ }^{83}$ Mugunga, J. C., et al. SARS-CoV-2 serosurveys in lowincome and middle-income countries. Lancet 2021. http s://doi.org/10.1101/2020.05.01.20087205.

${ }^{84}$ National Center for Immunization and Respiratory Diseases (NCIRD), D. of V.D. Interim Guidelines for Clinical Specimens for COVID-19 | CDC., 2021 [cited 2021 Mar 11]. https://www.cdc.gov/coronavirus/2019-ncov/la $\mathrm{b}$ /guidelines-clinical-specimens.html.

${ }^{85}$ Nielsen, K., et al. Development of a lateral flow assay for rapid detection of bovine antibody to Anaplasma marginale. J. Immunoass. Immunochem. 29:10-18, 2008.

${ }^{86}$ Nkengasong, J. N., and W. Mankoula. Looming threat of COVID-19 infection in Africa: Act collectively, and fast. Lancet 15:841-842, 2020.

${ }^{87}$ Ozsahin, I., B. Sekeroglu, M. S. Musa, M. T. Mustapha, and D. UzunOzsahin. Review on diagnosis of COVID-19 
from chest CT images using artificial intelligence. Comput. Math. Methods Med. 15:9756518, 2020.

${ }^{88}$ Paules, C. I., H. D. Marston, and A. S. Fauci. Coronavirus infections-more than just the common cold. JAMA 157:707-708, 2020.

${ }^{89}$ Qian, X., S. Tan, Z. Li, Q. Qu, L. Li, and L. Yang. A robust host-guest interaction controlled probe immobilization strategy for the ultrasensitive detection of HBV DNA using hollow HP5-Au/CoS nanobox as biosensing platform. Biosens. Bioelectron. 153:2020.

${ }^{90}$ Qin, L., et al. A water-stable metal-organic framework of a zwitterionic carboxylate with dysprosium: A sensing platform for Ebolavirus RNA sequences. Chem. Commun. 52:132-135, 2016.

${ }^{91}$ Qiu, G., Z. Gai, Y. Tao, J. Schmitt, G. A. Kullak-Ublick, and J. Wang. Dual-functional plasmonic photothermal biosensors for highly accurate severe acute respiratory syndrome coronavirus 2 detection. ACS Nano 2020. http s://doi.org/10.1021/acsnano.0c02439.

${ }^{92}$ Qiu, G. H., et al. Synchronous detection of ebolavirus conserved RNA sequences and ebolavirus-encoded miRNA-like fragment based on a zwitterionic copper(II) metal-organic framework. Talanta 180:396-402, 2018.

${ }^{93}$ Rebucci, A. Johns Hopkins economist: "Reopening an infected economy is no shortcut" to financial recovery Hub. [cited 2021 Mar 11]. https://hub.jhu.edu/2020/05/1 9/alessandro-rebucci-economic-impact-of-covid-19/.

${ }^{94}$ Ribeiro, B. V., T. A. R. Cordeiro, G. R. OliveiraeFreitas, L. F. Ferreira, and D. L. Franco. Biosensors for the detection of respiratory viruses: A review. Talanta 2:100007, 2020.

${ }^{95}$ Rosi, O.M.Y.E.L.K. Isoreticular metal-organic frameworks, process for forming the same, and systematic design of pore size and functionality therein,with application for gas storage. World Intellectual Property Organization, 2002.

${ }^{96}$ Roy, S., S.J. Malode, N.P. Shetti, and P. Chandra. Modernization of biosensing strategies for the development of lab-on-chip integrated systems. In: Bioelectrochemical Interface Engineering wiley, 2019, pp. 325-342.

${ }^{97}$ Safaei, M., M. M. Foroughi, N. Ebrahimpoor, S. Jahani, A. Omidi, and M. Khatami. A review on metal-organic frameworks: Synthesis and applications. 2019. https://doi. org/10.1016/j.trac.2019.06.007.

${ }^{98}$ Samanta, P., S. Let, W. Mandal, S. Dutta, and S.K. Ghosh. Luminescent metal-organic frameworks (LMOFs) as potential probes for the recognition of cationic water pollutants. Inorg. Chem. Front. 2020.

${ }^{99}$ Seitz, R. Human immunodeficiency virus (HIV). Transfus. Med. Hemotherapy 43:203-222, 2016.

${ }^{100}$ Sharp, P. M., and B. H. Hahn. Origins of HIV and the AIDS pandemic. Cold Spring Harb. Perspect. Med. 1:a006841, 2011

${ }^{101}$ Shetti, N.P., S.D. Bukkitgar, K.R. Reddy, C.V. Reddy, and T.M. Aminabhavi. ZnO-based nanostructured electrodes for electrochemical sensors and biosensors in biomedical applications. Biosens. Bioelectron. p. 111417, 2019.

${ }^{102}$ Stock, N., and S. Biswas. Synthesis of metal-organic frameworks (MOFs): Routes to various MOF topologies, morphologies, and composites. Chem. Rev. 2012. https://d oi.org/10.1021/cr200304e.

${ }^{103}$ Tahir, R., K. Rizwan, and M. Bilal. Metal-organic framework-based engineered materials-Fundamentals and applications. Molecules 25:1598, 2020.
${ }^{104}$ Tan, D.-X., A. Korkmaz, R. J. Reiter, and L. C. Manchester. Ebola virus disease: potential use of melatonin as a treatment. J. Pineal Res. 57:381-384, 2014. h ttps://doi.org/10.1111/jpi.12186.

${ }^{105}$ Tan, H., et al. A sensitive fluorescent assay for thiamine based on metal-organic frameworks with intrinsic peroxidase-like activity. Anal. Chim. Acta 856:90-95, 2015.

${ }^{106}$ Tang, Y.W., J.E. Schmitz, D.H. Persing, and C.W. Stratton. Laboratory diagnosis of COVID-19: Current issues and challenges. J. Clin. Microbiol.

${ }^{107}$ Thompson, D., and Y. Lei. Mini review: Recent progress in RT-LAMP enabled COVID-19 detection. Sens. Actuators Rep. 2:2020.

${ }^{108}$ Vardhanabhuti, V. CT scan AI-aided triage for patients with COVID-19 in China. Lancet Digit. Heal. Elsevier Ltd, pp. e494-e495, 2020.

${ }^{109}$ Velásquez-Hernández, M. D. J., et al. Degradation of ZIF-8 in phosphate buffered saline media. CrystEngComm 21:4538-4544, 2019.

${ }^{110}$ Vogelstein, B., and K. W. Kinzler. Digital PCR. Proc. Natl. Acad. Sci. USA 96:9236-9241, 1999.

${ }^{111}$ Wang, G. Y., C. Song, D. M. Kong, W. J. Ruan, Z. Chang, and Y. Li. Two luminescent metal-organic frameworks for the sensing of nitroaromatic explosives and DNA strands. J. Mater. Chem. A 2:2213-2220, 2014.

${ }^{112}$ Wang, H. S., et al. Insight into the unique fluorescence quenching property of metal-organic frameworks upon DNA binding. Anal. Chem. 89:11366-11371, 2017. http s://doi.org/10.1021/acs.analchem.7b02256.

${ }^{113}$ Wang, Y., et al. Metal-organic frameworks for virus detection. Biosens. Bioelectron. 169:2020.

${ }^{114}$ Wei, X., et al. Fluorescence biosensor for the H5N1 antibody based on a metal-organic framework platform. J. Mater. Chem. B 1:1812-1817, 2013.

${ }^{115}$ Won, J., et al. Development of a laboratory-safe and lowcost detection protocol for SARS-CoV-2 of the Coronavirus Disease 2019 (COVID-19). Exp. Neurobiol. 29:107119, 2020.

${ }^{116}$ World Health Organization. Zika virus., [cited 2021 Mar 15]. https://www.who.int/news-room/fact-sheets/detail/zik a-virus.

${ }^{117}$ World Health Organization. Dengue and severe dengue., [cited 2021 Mar 15]. https://www.who.int/news-room/factsheets/detail/dengue-and-severe-dengue.

${ }^{118}$ World Health Organization. HIV/AIDS., 2020 [cited 2021 Mar 12]. https://www.who.int/news-room/fact-sheets/deta il/hiv-aids.

${ }^{119}$ World Health Organization. Ebola virus disease., 2021 [cited 2021 Mar 14]. https://www.who.int/news-room/factsheets/detail/ebola-virus-disease.

${ }^{120}$ Worldometer. Coronavirus Update (Live): 118,684,343 Cases and 2,633,281 Deaths from COVID-19 Virus Pandemic - Worldometer. [cited 2021 Mar 11]. https://www. worldometers.info/coronavirus/.

${ }^{121} \mathrm{Wu}$, L.-L., et al. A metal-organic framework/DNA hybrid system as a novel fluorescent biosensor for mercury(II) ion detection. Chem. - A Eur. J. 22:477-480, 2016. https://doi. org/10.1002/chem.201503335.

${ }^{122}$ Xia, N., G. Wang, and W. Gong. Serological test is an efficient supplement for detecting RNA to confirm SARSCoV-2 infection. Preprint Preprints, 2020 [cited 2021 Mar 11]. www.preprints.org.

${ }^{123}$ Xiang, J., et al. Evaluation of enzyme-linked immunoassay and colloidal gold-immunochromatographic assay kit for detection of novel coronavirus (SARS-Cov-2) causing an 
outbreak of pneumonia (COVID-19). medRxiv 2020. htt ps://doi.org/10.1101/2020.02.27.20028787.

${ }^{124}$ Xie, B. P., et al. Simultaneous detection of Dengue and Zika virus RNA sequences with a three-dimensional $\mathrm{Cu}-$ based zwitterionic metal-organic framework, comparison of single and synchronous fluorescence analysis. Sens. Actuators B 254:1133-1140, 2018.

${ }^{125}$ Xie, X., Z. Zhong, W. Zhao, C. Zheng, F. Wang, and J. Liu. Chest CT for typical coronavirus disease 2019 (COVID-19) pneumonia: Relationship to negative RTPCR testing. Radiology 296:E41-E45, 2020.

${ }^{126}$ Xiong, C., W. Liang, Y. Zheng, Y. Zhuo, Y. Chai, and R. Yuan. Ultrasensitive assay for telomerase activity via selfenhanced electrochemiluminescent ruthenium complex doped metal-organic frameworks with high emission efficiency. Anal. Chem. 89:3222-3227, 2017. https://doi.org/ 10.1021 /acs.analchem.7b00259.

${ }^{127} \mathrm{Xu}, \mathrm{T}$., et al. Development of droplet digital PCR for the detection of Tilletia laevis, which causes common bunt of wheat, based on the SCAR marker derived from ISSR and real-time PCR. Sci. Rep. 10:16106, 2020. https://doi.org/ 10.1038/s41598-020-72976-7.

${ }^{128}$ Yang, H. M., X. L. Song, T. L. Yang, Z. H. Liang, C. M. Fan, and X. G. Hao. Electrochemical synthesis of flower shaped morphology MOFs in an ionic liquid system and their electrocatalytic application to the hydrogen evolution reaction. RSC Adv. 4:15720-15726, 2014.

${ }^{129}$ Yang, J., W. Feng, K. Liang, C. Chen, and C. Cai. A novel fluorescence molecularly imprinted sensor for Japanese encephalitis virus detection based on metal organic frameworks and passivation-enhanced selectivity. Talanta 212:2020.

${ }^{130}$ Yang, S. P., et al. Platforms formed from a three-dimensional $\mathrm{Cu}$-based zwitterionic metal-organic framework and probe ss-DNA: selective fluorescent biosensors for human immunodeficiency virus 1 ds-DNA and sudan virus rna sequences. Anal. Chem. 87:12206-12214, 2015. h ttps://doi.org/10.1021/acs.analchem.5b03084.

${ }^{131}$ Yang, S. P., et al. Platforms formed from a three-dimensional $\mathrm{Cu}$-based zwitterionic metal-organic framework and probe ss-DNA: selective fluorescent biosensors for human immunodeficiency virus 1 ds-DNA and sudan virus RNA sequences. Anal. Chem. 87:12206-12214, 2015. https://doi.org/10.1021/acs.analchem.5b03084.

${ }^{132}$ Yang, S. P., et al. Lanthanum-based metal-organic frameworks for specific detection of sudan virus RNA conservative sequences down to single-base mismatch. Inorg. Chem. 56:14880-14887, 2017.

${ }^{133}$ Yang, Y., et al. Laboratory diagnosis and monitoring the viral shedding of SARS-CoV-2 infection. Innov. 1:2020.

${ }^{134}$ Ye, Z., Y. Zhang, Y. Wang, Z. Huang, and B. Song. Chest CT manifestations of new coronavirus disease 2019
(COVID-19): a pictorial review. Eur. Radiol. 30:43814389, 2020.

${ }^{135}$ Yin, Y., et al. Protein-metal organic framework hybrid composites with intrinsic peroxidase-like activity as a colorimetric biosensing platform. ACS Appl. Mater. Interfaces 8:29052-29061, 2016. https://doi.org/10.1021/ac sami.6b09893.

${ }^{136} \mathrm{Yu}$, L., et al. Rapid detection of COVID-19 coronavirus using a reverse transcriptional loop-mediated isothermal amplification (RT-LAMP) diagnostic platform. Clin. Chem. 66:975-977, 2020.

${ }^{137}$ Yuan, S., et al. Stable metal-organic frameworks: design, synthesis, and applications. Adv. Mater. 30:1704303, 2018.

${ }^{138}$ Zafar, E.S. and F. Introductory Chapter: Metal Organic Frameworks (MOFs). In: Metal Organic Framework 2016, pp. 1-16.

${ }^{139}$ Zeng, H. H., W. BinQiu, L. Zhang, R. P. Liang, and J. D. Qiu. Lanthanide coordination polymer nanoparticles as an excellent artificial peroxidase for hydrogen peroxide detection. Anal. Chem. 88:6342-6348, 2016. https://doi.or $\mathrm{g} / 10.1021 /$ acs.analchem.6b00630.

${ }^{140}$ Zhao, H. Q., et al. A zinc(II)-based two-dimensional MOF for sensitive and selective sensing of HIV-1 ds-DNA sequences. Anal. Chim. Acta 922:55-63, 2016. https://doi. org/10.1016/j.aca.2016.03.054.

${ }^{141}$ Zhao, Y., Y. Yang, Y. Luo, X. Yang, M. Li, and Q. Song. Double detection of mycotoxins based on SERS labels embedded Ag@Au core-shell nanoparticles. ACS Appl. Mater. Interfaces. 7:21780-21786, 2015. https://doi.org/10. 1021/acsami.5b07804.

${ }^{142}$ Zhou, J., G. Tian, L. Zeng, X. Song, and X. Bian. Nanoscaled metal-organic frameworks for biosensing, imaging, and cancer therapy. Adv. Healthc. Mater. 7:1800022, 2018. https://doi.org/10.1002/adhm.201800022.

${ }^{143}$ Zhu, W., P. Liu, S. Xiao, W. Wang, D. Zhang, and H. Li. Microwave-assisted synthesis of Ag-doped MOFs-like organotitanium polymer with high activity in visible-light driven photocatalytic NO oxidization. Appl. Catal. B Environ. 172-173:46-51, 2015.

${ }^{144} \mathrm{Zhu}, \mathrm{X}$., et al. Metal-organic framework (MOF): A novel sensing platform for biomolecules. Chem. Commun. 49:1276-1278, 2013.

${ }^{145}$ Zhu, X. W., X. P. Zhou, and D. Li. Exceptionally water stable heterometallic gyroidal MOFs: Tuning the porosity and hydrophobicity by doping metal ions. Chem. Commun. 52:6513-6516, 2016.

Publisher's Note Springer Nature remains neutral with regard to jurisdictional claims in published maps and institutional affiliations. 